\title{
Impact of depatuxizumab mafodotin on health-related quality of life and neurological functioning in the phase II EORTC 1410/INTELLANCE 2 trial for EGFR-amplified recurrent glioblastoma
}

\author{
Clement, Paul M J ; Dirven, Linda ; Eoli, Marica ; Sepulveda-Sanchez, Juan M ; Walenkamp, \\ Annemiek M E ; Frenel, Jean S ; Franceschi, Enrico ; Weller, Michael ; et al
}

\begin{abstract}
BACKGROUND In the EORTC 1410/INTELLANCE 2 randomised, phase II study (NCT02343406), with the antibody-drug conjugate depatuxizumab mafodotin (Depatux-M, ABT-414) in patients with recurrent EGFR-amplified glioblastoma, the primary end-point (overall survival) was not met, and the drug had ocular dose-limiting toxicity. This study reports results from the prespecified health-related quality of life (HRQoL) and neurological deterioration-free survival (NDFS) exploratory analysis. PATIENTS AND METHODS Patients $(\mathrm{n}=260)$ were randomised 1:1:1 to receive either Depatux-M $1.25 \mathrm{mg} / \mathrm{kg}$ or $1.0 \mathrm{mg} / \mathrm{kg}$ intravenously every 2 weeks with oral temozolomide (TMZ) $150 \mathrm{mg} / \mathrm{m}^{2}$, Depatux-M alone, or TMZ or oral lomustine (CCNU) $110 \mathrm{mg} / \mathrm{m}^{2}$ (TMZ/CCNU). HRQoL outcomes were recorded using the EORTC core Quality of Life QLQ-C30, and brain cancer-specific QLQ-BN20 questionnaires. Questionnaires were completed at baseline, weeks 8 and 16 , and month 6 , and changes from baseline to each time point were calculated. NDFS was defined as time to first deterioration in World Health Organisation performance status. RESULTS Compliance with HRQoL was $88.1 \%$ at baseline and decreased to $37.9 \%$ at month 6. Differences from baseline between Depatux-M arms and TMZ/CCNU in global health/QoL status throughout treatment did not reach clinical relevance ( 10 points). Self-reported visual disorders deteriorated to a clinically relevant extent with Depatux-M arms versus TMZ/CCNU at all timepoints (mean differences range: 24.6-35.1 points). Changes from baseline for other HRQoL scales and NDFS were generally similar between treatment arms. CONCLUSIONS Depatux-M had no impact on HRQoL and NDFS in patients with EGFR-amplified recurrent glioblastoma, except for more visual disorders, an expected side-effect of the study drug. CLINICAL TRIAL REGISTRATION NCT02343406.
\end{abstract}

DOI: https://doi.org/10.1016/j.ejca.2021.01.010

Posted at the Zurich Open Repository and Archive, University of Zurich

ZORA URL: https://doi.org/10.5167/uzh-206263

Journal Article

Accepted Version

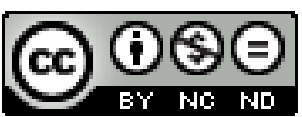

The following work is licensed under a Creative Commons: Attribution-NonCommercial-NoDerivatives 4.0 International (CC BY-NC-ND 4.0) License.

Originally published at: 
Clement, Paul M J; Dirven, Linda; Eoli, Marica; Sepulveda-Sanchez, Juan M; Walenkamp, Annemiek M E; Frenel, Jean S; Franceschi, Enrico; Weller, Michael; et al (2021). Impact of depatuxizumab mafodotin on health-related quality of life and neurological functioning in the phase II EORTC 1410/INTELLANCE 2 trial for EGFR-amplified recurrent glioblastoma. European Journal of Cancer, 147:1-12.

DOI: https://doi.org/10.1016/j.ejca.2021.01.010 


\section{European Journal of Cancer}

\section{Impact of depatuxizumab mafodotin on health-related quality of life and neurological functioning in the phase II EORTC 1410/INTELLANCE 2 trial for EGFR-amplified recurrent glioblastoma \\ --Manuscript Draft--}

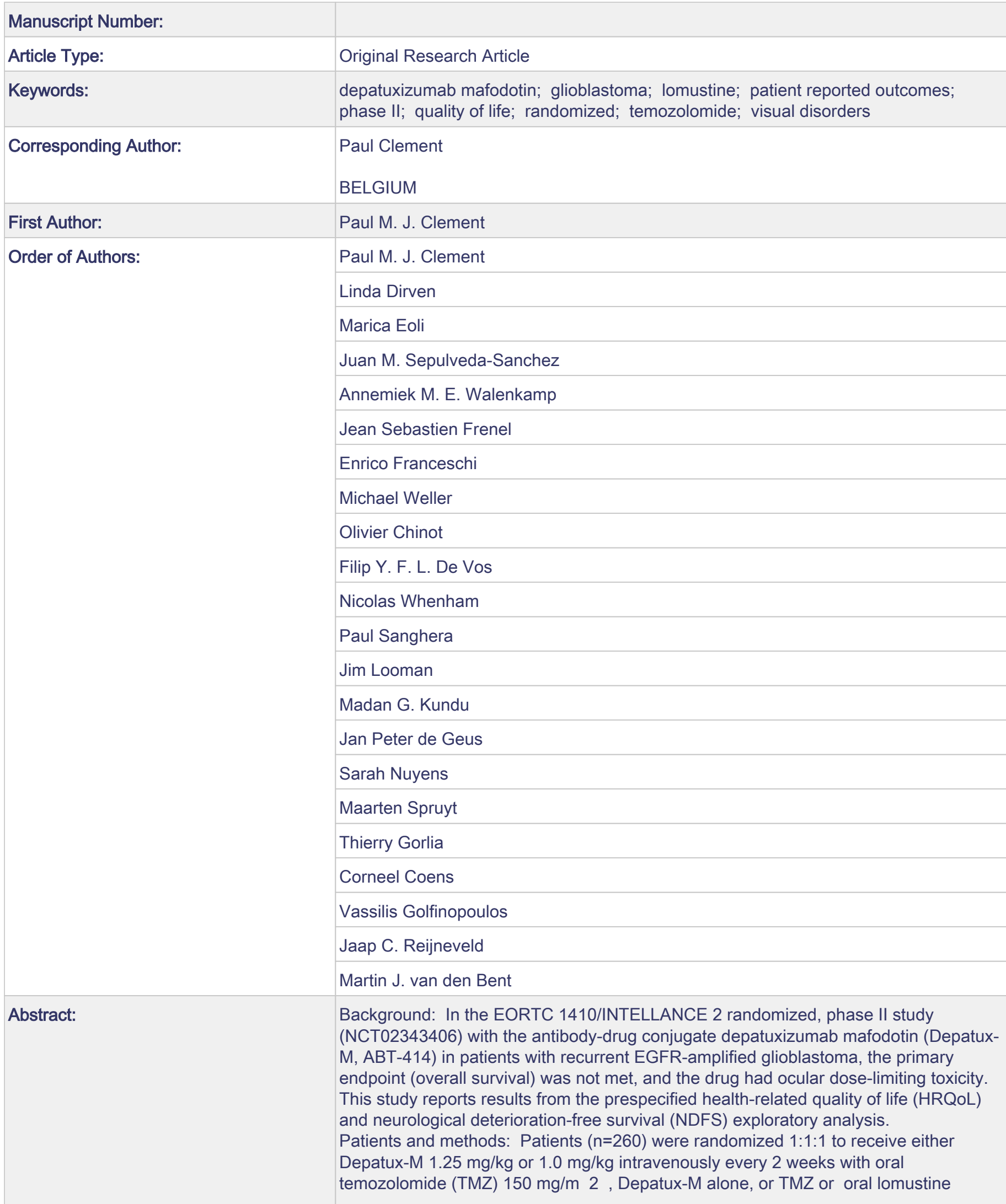




\begin{tabular}{|c|c|}
\hline & $\begin{array}{l}\text { (CCNU) } 110 \mathrm{mg} / \mathrm{m} 2 \text { (TMZ/CCNU). HRQoL outcomes were recorded using the } \\
\text { EORTC core Quality of Life QLQ-C30, and brain cancer-specific QLQ-BN20 } \\
\text { questionnaires. Questionnaires were completed at baseline, Weeks } 8 \text { and } 16 \text {, and } \\
\text { Month 6, and changes from baseline to each time point were calculated. NDFS was } \\
\text { defined as time to first deterioration in WHO performance status. } \\
\text { Results: Compliance with HRQoL was } 88.1 \% \text { at baseline and decreased to } 37.9 \% \text { at } \\
\text { Month 6. Differences from baseline between Depatux-M arms and TMZ/CCNU in } \\
\text { global health/QoL status throughout treatment did not reach clinical relevance ( } \geq 10 \\
\text { points). Self-reported visual disorders deteriorated to a clinically relevant extent with } \\
\text { Depatux-M arms vs. TMZ/CCNU at all timepoints (mean differences range: } 24.6-35.1 \\
\text { points). Changes from baseline for other HRQL scales and NDFS were generally } \\
\text { similar between treatment arms. } \\
\text { Conclusions: Depatux-M had no impact on HRQoL and NDFS in patients with EGFR- } \\
\text { amplified recurrent glioblastoma, except for more visual disorders, an expected side } \\
\text { effect of the study drug. }\end{array}$ \\
\hline \multirow[t]{4}{*}{ Suggested Reviewers: } & $\begin{array}{l}\text { Martin Taphoorn } \\
\text { m.j.b.taphoorn@lumc.nl }\end{array}$ \\
\hline & $\begin{array}{l}\text { Matthias Preusser } \\
\text { Matthias.preusser@meduniwien.ac.au }\end{array}$ \\
\hline & $\begin{array}{l}\text { Ann Hoeben } \\
\text { ann.hoeben@mumc.nl }\end{array}$ \\
\hline & $\begin{array}{l}\text { Ahmed Idbaih } \\
\text { ahmed.idbaih@psl.aphp.fr }\end{array}$ \\
\hline
\end{tabular}


December 2020

Alexander M. M. Eggermont, MD, PhD

Editor-in-Chief

European Journal of Cancer

RE: Impact of depatuxizumab mafodotin on health-related quality of life and neurological functioning in glioblastoma.

Dear Prof. Eggermont,

We are pleased to submit our manuscript, "Impact of depatuxizumab mafodotin on health-related quality of life and neurological functioning in the phase II EORTC 1410/INTELLANCE 2 trial for EGFR-amplified recurrent glioblastoma," for consideration as an original research article in the European Journal of Cancer.

Depatuxizumab mafodotin (Depatux-M) is an EGFR antibody - monomethyl auristatin F drug conjugate that has recently been evaluated in the EORTC 1410/INTELLANCE 2 randomized, phase II trial in patients with recurrent EGFR-amplified glioblastoma. In this study, Depatux-M in combination with temozolomide provided a non-statistically significant improvement in overall survival in these patients compared with temozolomide/lomustine (standard of care). In this study, grade 3/4 ocular toxicity with Depatux-M plus temozolomide was reported in 32.9\% of patients. In this manuscript we evaluated health-related quality of life measurements and neurological deterioration-free survival of patients from this study and observed similar changes from baseline for most of these outcomes in patients treated with Depatux-M, Depatux-M plus temozolomide, and standard of care. The only exception was self-reported visual disorders, which deteriorated to a clinically relevant extent with both Depatux-M arms compared with standard of care at all timepoints (mean differences range: 24.6-35.1 points).

We believe readers of the European Journal of Cancer will find this manuscript of interest as it provides additional insight on the issues with the development of EGFR antibody-drug conjugates for the treatment of glioblastoma.

This is an EORTC study that was supported by AbbVie Inc. All authors contributed to manuscript development and reviewed and approved the content of the submitted manuscript. The submitted article has not been published, nor is it under consideration for publication elsewhere.

We would like to propose the following reviewers for this manuscript:

Martin Taphoorn, Leiden (m.j.b.taphoorn@lumc.nl)

Matthias Preusser, Vienna (Matthias.preusser@meduniwien.ac.au)

Ann Hoeben, Maastricht (ann.hoeben@mumc.nl)

Ahmed Idbaih, Paris (ahmed.idbaih@psl.aphp.fr) 
We look forward to your response.

Sincerely,

Dr. Paul M. J. Clement, MD, PhD

Department of Oncology

Leuven Cancer Institute, KU Leuven

Herestraat 49, BE-3000 Leuven, Belgium

E-mail: paul.clement@uzleuven.be 


\section{Highlights}

(3-5 $\leq 85$-character [including spaces] bullets presenting core findings of study)

- Clinically relevant increases in self-reported visual disorders with Depatux-M.

- Similar health-related quality of life scores between Depatux-M and standard care.

- Neurological deterioration-free survival was similar between treatments. 


\section{Impact of depatuxizumab mafodotin on health-related quality of life and neurological functioning in the phase II EORTC 1410/INTELLANCE 2 trial for EGFR-amplified recurrent glioblastoma}

Paul M. J. Clement ${ }^{\mathrm{a}}$, Linda Dirven ${ }^{\mathrm{b}, \mathrm{c}}$, Marica Eoli ${ }^{\mathrm{d}}$, Juan M. Sepulveda-Sanchez ${ }^{\mathrm{e}}$, Annemiek M. E. Walenkamp ${ }^{\mathrm{f}}$, Jean Sebastien Frenel ${ }^{\mathrm{g}}$, Enrico Franceschi ${ }^{\mathrm{h}}$, Michael Weller ${ }^{\mathrm{i}}$, Olivier Chinot ${ }^{\mathrm{j}}$, Filip Y. F. L. De Vos ${ }^{\mathrm{k}}$, Nicolas Whenham ${ }^{1}$, Paul Sanghera ${ }^{\mathrm{m}}$, Jim Looman ${ }^{\mathrm{n}}$, Madan G. Kundu ${ }^{\circ}$, Jan Peter de Geus ${ }^{\mathrm{p}}$, Sarah Nuyens ${ }^{\mathrm{q}}$, Maarten Spruyt ${ }^{\mathrm{r}}$, Thierry Gorlia ${ }^{\mathrm{s}}$, Corneel Coens ${ }^{\mathrm{t}}$, Vassilis Golfinopoulos ${ }^{\mathrm{u}}$, Jaap C. Reijneveld ${ }^{\mathrm{v}, \mathrm{w}}$, Martin J. van den Bent ${ }^{\mathrm{x}}$

${ }^{a}$ Department of Oncology, Leuven Cancer Institute, KU Leuven, Leuven, Belgium, paul.clement@uzleuven.be; bDepartment of Neurology, Leiden University Medical Center, Leiden, the Netherlands, 1.dirven@lumc.nl; 'Department of Neurology, Haaglanden Medical Center, The Hague, the Netherlands; ${ }^{\mathrm{d}}$ Unit of Molecular Neuro-Oncology, Fondazione IRCCS Istituto Neurologico Carlo Besta, Milan, Italy, marica.eoli @istituto-besta.it; ${ }^{\circ}$ Hospital Universitario 12 de Octubre, Madrid, Spain, jmsepulveda76@gmail.com; fDepartment of Medical Oncology, University Medical Centre Groningen, University of Groningen, Groningen, the Netherlands, a.walenkamp@ umcg.nl; ${ }^{9}$ Medical Oncology, Institut de Cancerologie de l’Ouest, Saint-Herblain, France, Jean-Sebastien.Frenel@ico.unicancer.fr; ${ }^{\text {h} M e d i c a l ~ O n c o l o g y ~}$ Department, AUSL / IRCCS Institute of Neurological Sciences, Bologna, Italy, enricofra@yahoo.it; i Department of Neurology, University Hospital and University of Zurich, Zurich, Switzerland, michael.weller@ usz.ch; ${ }^{\mathrm{j} A i x}$-Marseille Univ, APHM, CNRS, INP, Inst Neurophysiopathol, CHU Timone, Service de Neuro-Oncologie, Marseille, France, 
olivier.chinot@ap-hm.fr; ${ }^{k}$ Department of Medical Oncology, University Medical Center Utrecht, University Utrecht, Utrecht, the Netherlands, f.devos@ umcutrecht.nl; ${ }^{1}$ Cliniques Universitaires Saint-Luc, Brussels, Belgium, nicolas.whenham@uclouvain.be; ${ }^{\mathrm{m}}$ University Hospitals Birmingham, Edgbaston, Birmingham, United Kingdom, paul.sanghera@uhb.nhs.uk; nPharmaceutical Development, AbbVie, Hoofddorp, the Netherlands, jim.looman@abbvie.com;

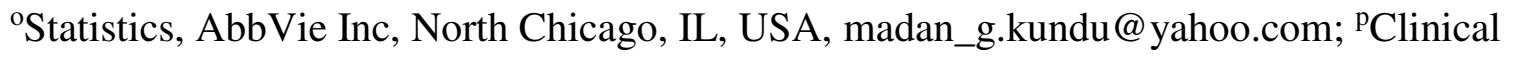
Program Development, AbbVie, Hoofddorp, the Netherlands, jan.peter.de.geus@abbvie.com; qEORTC, Brussels, Belgium, sarah.nuyens@eortc.org; ' $\mathrm{E}$ @ORTC, Brussels, Belgium, maarten.spruyt@eortc.org; 'EORTC Headquarters, Brussels, Belgium, thierry.gorlia@eortc.org; tEORTC Headquarters, Brussels, Belgium, corneel.coens@eortc.org; "EORTC Headquarters, Brussels, Belgium, Vassilis.golfinopoulos@eortc.org; Brain Tumor Center Amsterdam, Amsterdam University Medical Centers, Amsterdam, the Netherlands, jc.reijneveld@amsterdamumc.nl; " Stichting Epilepsie Instellingen Nederland (SEIN), Heemstede, the Netherlands; ${ }^{x}$ Department of Neurology, Brain Tumor Center at Erasmus MC Cancer Institute, University Medical Center Rotterdam, Rotterdam, the Netherlands, m.vandenbent@erasmusmc.nl

Target journal: European Journal of Cancer

Word count limit: 2,500 (Currently 2,588)

Reference limit: 40 (Currently 40)

Table/figure limit: Not indicated (Currently 8) 
Corresponding author:

Dr. Paul M. J. Clement, MD, PhD

Department of Oncology

Leuven Cancer Institute, KU Leuven

Herestraat 49, BE-3000 Leuven, Belgium

E-mail: paul.clement@uzleuven.be

\section{Role of the funding source}

This is an independent EORTC study that was funded by AbbVie Inc. The contributions of the authors acting on behalf of EORTC and AbbVie Inc., are listed below. All authors contributed to the development of the publication and maintained control over the final content.

\section{Acknowledgements}

We are grateful to AbbVie for supporting this independent EORTC study. We thank Arijit Ganguli for his contribution in the development of this manuscript. We thank Alan Saltzman of Fishawack Facilitate Ltd, part of Fishawack Health, for medical writing support (funded by AbbVie). 
Abstract (250 words, currently 250)

Background: In the EORTC 1410/INTELLANCE 2 randomized, phase II study (NCT02343406) with the antibody-drug conjugate depatuxizumab mafodotin (Depatux-M, ABT414) in patients with recurrent EGFR-amplified glioblastoma, the primary endpoint (overall survival) was not met, and the drug had ocular dose-limiting toxicity. This study reports results from the prespecified health-related quality of life (HRQoL) and neurological deterioration-free survival (NDFS) exploratory analysis.

Patients and methods: Patients $(n=260)$ were randomized 1:1:1 to receive either Depatux-M $1.25 \mathrm{mg} / \mathrm{kg}$ or $1.0 \mathrm{mg} / \mathrm{kg}$ intravenously every 2 weeks with oral temozolomide (TMZ) $150 \mathrm{mg} / \mathrm{m}^{2}$, Depatux-M alone, or TMZ or oral lomustine (CCNU) $110 \mathrm{mg} / \mathrm{m}^{2}$ (TMZ/CCNU). HRQoL outcomes were recorded using the EORTC core Quality of Life QLQ-C30, and brain cancer-specific QLQ-BN20 questionnaires. Questionnaires were completed at baseline, Weeks 8 and 16, and Month 6, and changes from baseline to each time point were calculated. NDFS was defined as time to first deterioration in WHO performance status.

Results: Compliance with HRQoL was $88.1 \%$ at baseline and decreased to $37.9 \%$ at Month 6 . Differences from baseline between Depatux-M arms and TMZ/CCNU in global health/QoL status throughout treatment did not reach clinical relevance $(\geq 10$ points). Self-reported visual disorders deteriorated to a clinically relevant extent with Depatux-M arms vs. TMZ/CCNU at all timepoints (mean differences range: 24.6-35.1 points). Changes from baseline for other HRQoL scales and NDFS were generally similar between treatment arms.

Conclusions: Depatux-M had no impact on HRQoL and NDFS in patients with EGFR-amplified recurrent glioblastoma, except for more visual disorders, an expected side effect of the study drug. 
Clinical trial registration: NCT02343406.

Keywords (MeSH: up to 10): depatuxizumab mafodotin; glioblastoma; lomustine;

patient-reported outcomes; phase II; quality of life; randomized; temozolomide; visual disorders. 


\section{Introduction}

Glioblastoma is the most common and aggressive type of malignant primary brain tumor worldwide, with an incidence rate of 3.2 total and 0.48 for adolescents and young adults per 100,000 persons in the United States [1-3]. For patients with glioblastoma, the survival rate is poor, with about $5 \%$ of patients surviving after 5 years [1]. Glioblastoma has a major impact on the lives of patients and their informal caregivers, with both physical and psychological healthrelated quality of life (HRQoL) aspects adversely affected by this disease [4]. HRQoL can not only be negatively influenced by the tumor itself, but also by both supportive and anti-tumor treatments as well as non-tumor related issues, such as comorbidities [5].

Current standard of care for newly diagnosed glioblastoma consists of surgery followed by chemoradiotherapy with temozolomide (TMZ) [6, 7]. Alternating electric field therapy is an additional option [6]. However, to date, patients cannot be cured, and relapse is inevitable with only suboptimal treatment options in second line therapy available [6, 7]. Therefore, alternative strategies to treat glioblastoma need to be developed.

Epidermal growth factor receptor (EGFR) gene amplification occurs in approximately $50 \%$ of glioblastomas and therefore represents a promising tumor-specific target [8-11]. EGFR amplification is maintained in more than $80 \%$ of recurrent glioblastomas [12]. For approximately $50 \%$ of these EGFR-amplified tumors, a constitutively active variant III mutation (EGFRvIII) is present [13]. However, trials for glioblastoma investigating EGFR inhibitors, including tyrosine kinase inhibitors and EGFR-directed antibodies, have failed to improve survival [14-21]. 
Depatuxizumab mafodotin (Depatux-M, formerly known as ABT-414) is an antibody-drug

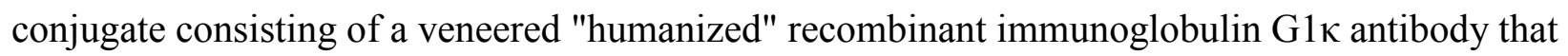
has binding properties specific to a unique epitope of human EGFR, with non-cleavable maleimidocaproyl linkers attached to a potent antimicrotubule agent, monomethyl auristatin $\mathrm{F}$ [22]. In phase I studies, Depatux-M was shown to have potential activity for patients with newly diagnosed or recurrent glioblastoma [23-26]. Ocular toxicity consisting of a corneal epitheliopathy was dose limiting and the most observed toxicity in these studies, with $22 \%-33 \%$ of patients having grade 3 or 4 toxicities $[23,24,26]$. Ocular toxicity was generally reversible with symptomatic treatment and discontinuation of Depatux-M [23, 24, 26].

Recently, safety and efficacy results were reported for the European Organization for Research and Treatment of Cancer (EORTC) 1410/INTELLANCE 2 randomized, phase II study (NCT02343406) for patients with recurrent EGFR-amplified glioblastoma treated with either Depatux-M alone, Depatux-M plus TMZ, or standard of care (lomustine [CCNU] or TMZ) [27]. The most frequent grade 3 or 4 toxicities were ocular, with $32.9 \%$ and $23.8 \%$ of patients reporting this level of ocular toxicity for the combination and single agent therapies, respectively [27]. Overall survival did not improve significantly with combination therapy vs. standard of care (hazard ratio: $0.71 ; 95 \%$ confidence interval $[\mathrm{CI}]$ : $0.50-1.02, P=0.06$, median follow-up 14.4 months) [27]. In this report, we present results on the impact of Depatux-M on HRQoL aspects, as well as on neurological deterioration (ND)-free survival (NDFS), which were exploratory endpoints in this study. 


\section{Materials and methods}

\subsection{Study design and patients}

EORTC 1410 was a randomized, international, open-label multi-arm phase II study. Full study details and results have been published previously [27]. Further details are described in supplementary materials. Both NDFS and HRQoL were prespecified exploratory endpoints.

\subsection{Measures and procedures}

HRQoL was measured using two questionnaires: the EORTC Quality of Life Questionnaire (QLQ-C30) version 3.0 [28] and the Quality of Life Questionnaire Brain Cancer Module (QLQBN20) [5] totaling 50 questions which were transformed into 26 scales according to a standardized scoring procedure [29]. Both questionnaires have been validated [5, 28] and translated into more than 110 languages [30]. Further details are described in supplementary materials.

Patients completed the paper HRQoL questionnaires at baseline; at Weeks 8 and 16 while on treatment; and at 6 months after randomization, regardless of treatment or progression status. Because of the potential for bias, differences in compliance between treatment arms were assessed at each time point. Compliance was defined as the ratio of valid HRQoL forms received divided by the HRQoL forms expected for the time window of the respective time point.

NDFS, a separate exploratory endpoint, was also evaluated. NDFS was defined as the time to first deterioration in World Health Organization (WHO) performance status (that was maintained for at least 3 weeks and for which no other explanation was apparent) or death, whichever 
occurred first. For patients with a baseline WHO performance status of 0 or 1 , deterioration was defined as 2 or worse; for patients with WHO performance status of 2 at baseline, deterioration was defined as 3 or worse. ND was measured from randomization to first deterioration or death, regardless of radiological progression. WHO performance status was assessed at baseline, at every treatment visit, every 12 weeks during follow-up, and at time of NDFS evaluation. WHO performance status was assessed beyond progression and discontinuation of treatment. Patients without ND were censored at the time of last WHO performance status assessment.

\subsection{Statistical analyses}

HRQoL data were scored according to the algorithm described in the EORTC scoring manual [29] resulting in ordinal scales on a 0-100 range. A higher score on a functional scale represents better functioning, while a higher score on a symptom scale represents more symptomatology. A change of $\geq 10$ points was considered clinically relevant [31]. A patient's status was classified as improved, stable, or deteriorated according to the 10-point change threshold for changes in HRQoL scores per time point, relative to baseline. The primary HRQoL endpoint for this study was clinically relevant change from baseline in the global health status/quality of life (QoL) scale at Weeks 8 and 16, and Month 6. Secondary HRQoL endpoints assessed were the clinically relevant change from baseline in the other QLQ-C30 and QLQ-BN20 scales, except for financial difficulties, which was excluded. Statistical significance was calculated by the Kruskal-Wallis test, a non-parametric rank analysis of variance test [32]. This test was selected because it does not require the groups to be normally distributed and is more stable to outliers. Further details are described in the supplementary materials. 
Time to event endpoints for NDFS was determined using the Kaplan-Meier method. The NDFS probability at $6,12,18$, and 24 months; median NDFS; and hazard ratios were estimated from the Kaplan-Meier NDFS curves and compared using a log-rank test, stratified for the stratification factors at randomization. Two-sided 95\% CIs were computed based on the Greenwood's formula. For the median, the Reflected Method provided two-sided 95\% CIs. All analyses were done using SAS version 9.4. 


\section{Results}

\subsection{Patient characteristics and compliance with HRQoL outcomes}

A total of 260 patients were enrolled in the study (Supplementary Fig. 1). Baseline demographics and clinical characteristics of patients included in this analysis were comparable between study arms (Supplementary Table 1). Compliance with HRQoL assessment was comparable across treatment arms and decreased during the trial from 88.1\% (229/260) at baseline to 37.9\% at Month 6 (66/174; Supplementary Table 2). HRQoL compliance was not significantly associated with treatment arm or baseline covariates of region, WHO performance status ( 0 vs. 1 , vs. 2$)$, timing of relapse ( $<16$ weeks vs. $\geq 16$ weeks after the first day of the last TMZ cycle), gender, or age ( $<60$ vs. $\geq 60$ years of age). No correlation was observed between compliance and ocular toxicity.

\subsection{Impact of Depatux-M on overall global health/QoL status}

At all time points, differences from baseline between the Depatux-M treatment arms and the TMZ/CCNU treatment arm in global health/QoL status were not clinically relevant $(<10$ points,

Table 1). At Week 8, global health/QoL status decreased in all treatment groups, with a clinically relevant decrease $(\geq 10$ points) for the Depatux-M monotherapy group $(-11.5, \mathrm{SE}=3.5)$ compared with baseline (Fig. 1 and Table 1). At Week 16 and Month 6, scores were improved compared with scores at Week 8 in all treatment arms; mean changes from baseline were not clinically relevant. Overall, there were no major differences between the three treatment arms in overall global health/QoL status during the treatment period. 
Table 1. Global health/QoL status changes with Depatux-M

\begin{tabular}{|c|c|c|c|}
\hline & $\underset{(\mathrm{n}=\mathbf{8 8})}{\text { Depatux-M + TMZ }}$ & $\begin{array}{l}\text { Depatux-M } \\
(\mathbf{n}=\mathbf{8 6})\end{array}$ & $\begin{array}{c}\text { TMZ/CCNU } \\
(\mathbf{n}=\mathbf{8 6})\end{array}$ \\
\hline \multicolumn{4}{|l|}{ Baseline } \\
\hline $\mathrm{n}$ & 78 & 69 & 77 \\
\hline median (range) & $66.7(8.3$ to 100.0$)$ & $58.3(0.0$ to 100.0$)$ & 66.7 (0.0 to 100.0$)$ \\
\hline mean $(\mathrm{SE})$ & $63.0(2.6)$ & $57.5(2.8)$ & $61.4(2.6)$ \\
\hline \multicolumn{4}{|l|}{ Week 8} \\
\hline $\mathrm{n}$ & 54 & 38 & 37 \\
\hline median (range) & $58.3(0.0$ to 100.0$)$ & 50.0 (16.7 to 91.7$)$ & $58.3(0.0$ to 100.0$)$ \\
\hline mean $(\mathrm{SE})$ & $57.1(3.2)$ & $49.8(3.1)$ & $57.2(4.0)$ \\
\hline \multicolumn{4}{|l|}{ Change from baseline } \\
\hline $\mathrm{n}$ & 47 & 34 & 33 \\
\hline mean $(\mathrm{SE})$ & $-6.9(3.4)$ & $-11.5(3.5)$ & $-6.6(3.8)$ \\
\hline $\begin{array}{l}\text { Difference from TMZ/CCNU, } \\
\text { mean }(95 \% \mathrm{CI})\end{array}$ & $-0.4(-10.3,9.6)$ & $-5.0(-15.7,5.7)$ & - \\
\hline \multicolumn{4}{|l|}{ Week 16} \\
\hline $\mathrm{n}$ & 30 & 19 & 16 \\
\hline median (range) & $66.7(33.3$ to 100.0$)$ & $58.3(33.3$ to 100.0$)$ & 66.7 (33.3 to 100.0$)$ \\
\hline mean (SD) & $65.0(3.5)$ & $63.2(4.0)$ & $63.5(4.7)$ \\
\hline \multicolumn{4}{|l|}{ Change from baseline } \\
\hline $\mathrm{n}$ & 26 & 17 & 14 \\
\hline mean $(\mathrm{SE})$ & $-4.2(4.1)$ & $2.0(6.5)$ & $-1.2(4.9)$ \\
\hline $\begin{array}{l}\text { Difference from TMZ/CCNU, } \\
\text { mean }(95 \% \mathrm{CI})\end{array}$ & $-3.0(-17.8,11.9)$ & $3.2(-13.0,19.3)$ & - \\
\hline \multicolumn{4}{|l|}{ Month 6} \\
\hline $\mathrm{n}$ & 27 & 20 & 16 \\
\hline median (range) & $66.7(0.0$ to 91.7$)$ & $50.0(8.3$ to 100.0$)$ & $66.7(8.3$ to 83.3$)$ \\
\hline mean (SE) & $60.5(4.5)$ & $56.3(5.4)$ & $64.1(5.4)$ \\
\hline \multicolumn{4}{|l|}{ Change from baseline } \\
\hline $\mathrm{n}$ & 25 & 19 & 17 \\
\hline mean $(\mathrm{SE})$ & $-1.3(4.7)$ & $0.0(6.5)$ & $-1.0(4.8)$ \\
\hline $\begin{array}{l}\text { Difference from TMZ/CCNU, } \\
\text { mean }(95 \% \mathrm{CI})\end{array}$ & $0.4(-15.6,14.8)$ & $1.0(-15.2,17.1)$ & - \\
\hline \multicolumn{4}{|c|}{ All scales and single items were scored on categorical scales and linearly converted into 0-100 } \\
\hline \multicolumn{4}{|c|}{ scales. Analyses of change from baseline were based on a Kruskal-Wallis test including } \\
\hline \multicolumn{4}{|l|}{ treatment as the sole factor. } \\
\hline \multicolumn{4}{|c|}{ CCNU, lomustine; CI, confidence interval; Depatux-M, depatuxizumab mafodotin; QoL, quality } \\
\hline
\end{tabular}


Fig. 1. Mean change from baseline in global health/QoL status in the three treatment arms

CCNU, lomustine; Depatux-M, depatuxizumab mafodotin; QoL, quality of life; TMZ,

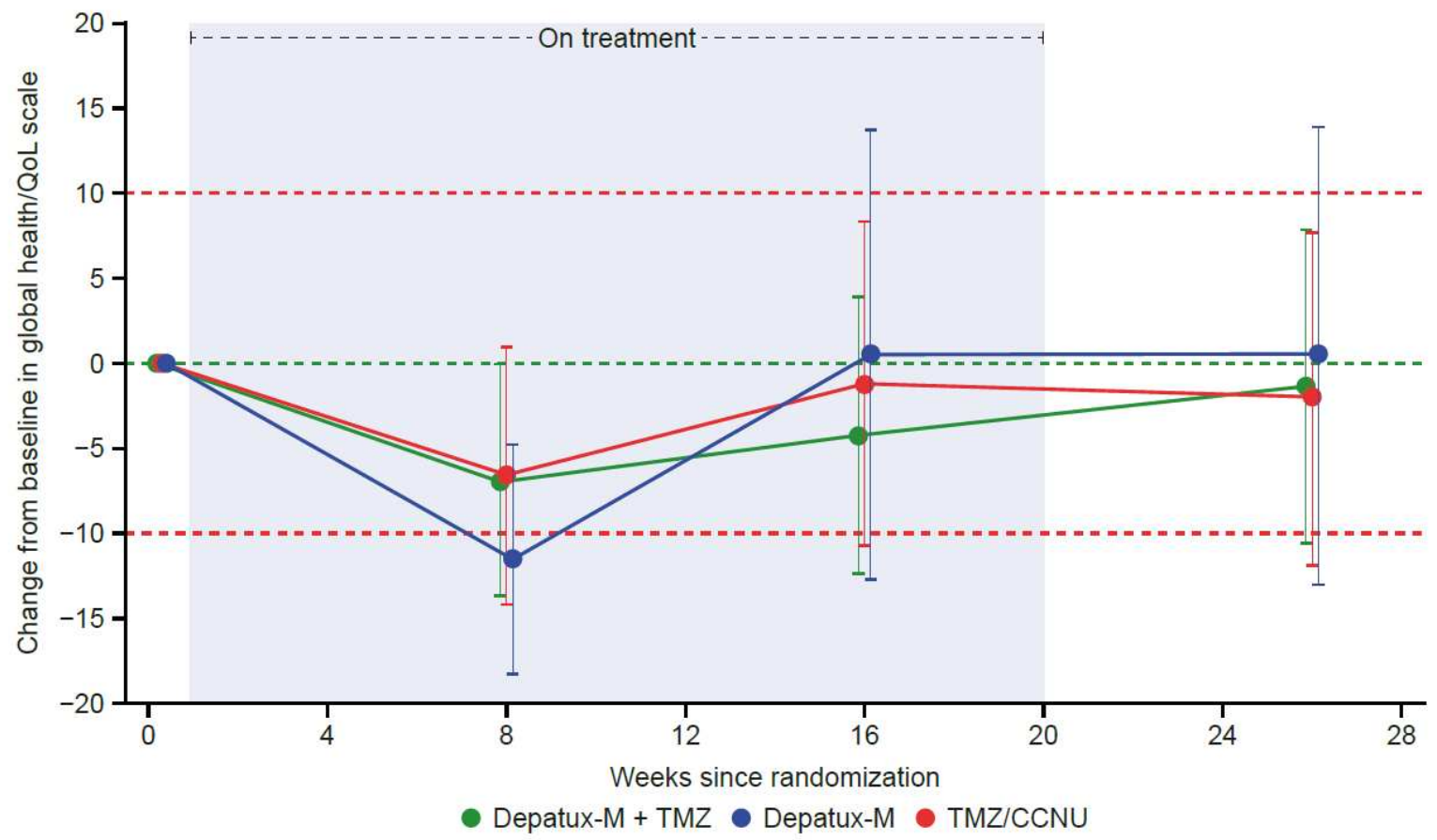

Number of patients observed

$\begin{array}{lcccc} & \text { Baseline } & \text { Week } 8 & \text { Week 16 } & \text { Month } 6 \\ \text { DepatuX-M + TMZ } & 78 & 47 & 26 & 25 \\ \text { DepatuX-M } & 69 & 34 & 16 & 18 \\ \text { TMZ/CCNU } & 77 & 33 & 14 & 16\end{array}$

temozolomide.

Error bars represent $95 \%$ confidence intervals. 
The percentage of patients with a clinically relevant change from baseline in global health/QoL values was not significantly different across the treatment arms (Table 2). Generally, a similar percentage of patients had a clinically relevant increase or decrease in global health status/QoL, while the remaining patients had stable scores, irrespective of treatment arm and follow-up time point.

Table 2. Number of patients with a clinical difference of $\geq \mathbf{1 0}$ points in global health/QoL status from baseline

\begin{tabular}{lccc}
\hline & $\begin{array}{c}\text { Depatux-M + TMZ } \\
(\mathbf{n = 8 8})\end{array}$ & $\begin{array}{c}\text { Depatux-M } \\
(\mathbf{n = 8 6})\end{array}$ & $\begin{array}{c}\text { TMZ/CCNU } \\
(\mathbf{n = 8 6})\end{array}$ \\
\hline Week 8 & 54 & 38 & 37 \\
Number of observations & $18(33.3)$ & $13(34.2)$ & $16(43.2)$ \\
Deteriorated, n (\%) & $22(40.7)$ & $17(44.7)$ & $13(35.1)$ \\
Stable, n (\%) & $14(25.9)$ & $8(21.1)$ & $8(21.6)$ \\
Improved, n (\%) & 0.3788 & 0.5891 & - \\
$P$-value (vs. TMZ/CCNU) & & & 16 \\
Week 16 & 30 & $5(26.3)$ & $6(37.5)$ \\
Number of observations & $10(33.3)$ & $7(36.8)$ & $5(31.3)$ \\
Deteriorated, n $(\%)$ & $11(36.7)$ & $7(36.8)$ & $5(31.3)$ \\
Stable, n $(\%)$ & $9(30.0)$ & 0.5505 & - \\
Improved, n $(\%)$ & 0.9026 & & 16 \\
$P$-value (vs. TMZ/CCNU) & & 20 & $5(31.3)$ \\
Month 6 & 27 & $7(35.0)$ & $7(43.8)$ \\
Number of observations & $5(18.5)$ & $6(30.0)$ & $4(25.0)$ \\
Deteriorated, n $(\%)$ & $14(51.9)$ & $7(35.0)$ & - \\
Stable, $n(\%)$ & $8(29.6)$ & 0.8262 & \\
Improved, n (\%) & 0.4535 & & \\
$P$-value (vs. TMZ/CCNU) & & & \\
\hline
\end{tabular}

Deteriorated: $\geq 10$-point decrease. Improved: $\geq 10$-point increase.

CCNU, lomustine; Depatux-M, depatuxizumab mafodotin; QoL, quality of life; TMZ, temozolomide. 


\subsection{Impact of Depatux-M on other HRQoL scales}

Generally, changes from baseline for physical, cognitive, social, role, and emotional functioning did not reach clinical relevance for the cohorts treated with Depatux-M compared with those treated with TMZ/CCNU (Table 3 and Supplementary Table 3). For cognitive functioning, a clinically relevant decrease from baseline was observed for the Depatux-M plus TMZ and Depatux-M treatment arms vs. the TMZ/CCNU treatment arm at Week 8 (difference [95\% CI]

$-12.6[-23.3,-1.8]$ and $-15.8[-29.0,-2.6]$, respectively), but not at Week 16 or Month 6. 
Table 3. Change from baseline with Depatux-M relative to TMZ/CCNU in QLQ-C30

functioning scale scores

\begin{tabular}{|c|c|c|}
\hline $\begin{array}{l}\text { Difference from TMZ/CCNU, } \\
\text { mean }(95 \% \mathrm{CI}), \mathbf{n}\end{array}$ & $\begin{array}{c}\text { Depatux-M + TMZ } \\
(\mathrm{n}=88)\end{array}$ & $\begin{array}{c}\text { Depatux-M } \\
(n=86)\end{array}$ \\
\hline \multicolumn{3}{|l|}{ Cognitive functioning } \\
\hline Week 8 & $-12.6(-23.3,-1.8), 47$ & $-15.8(-29.0,-2.6), 34$ \\
\hline Week 16 & $0.2(-15.3,15.7), 26$ & $-3.4(-23.2,16.3), 16$ \\
\hline Month 6 & $-1.2(-20.4,18.1), 25$ & $-7.9(-31.1,15.4), 18$ \\
\hline \multicolumn{3}{|l|}{ Emotional functioning } \\
\hline Week 8 & $3.9(-5.5,13.2), 47$ & $-1.2(-12.2,9.9), 34$ \\
\hline Week 16 & $-5.8(-19.5,7.9), 26$ & $-2.8(-20.7,15.2), 16$ \\
\hline Month 6 & $2.6(-12.8,17.9), 25$ & $0.3(-15.1,15.8), 18$ \\
\hline \multicolumn{3}{|l|}{ Physical functioning } \\
\hline Week 8 & $-0.7(-9.4,8.0), 48$ & $-3.4(-12.0,5.3), 34$ \\
\hline Week 16 & $1.4(-8.9,11.7), 26$ & $-2.3(-12.4,7.7), 16$ \\
\hline Month 6 & $-4.8(-19.4,9.8), 25$ & $-9.2(-25.4,7.0), 18$ \\
\hline \multicolumn{3}{|l|}{ Role functioning } \\
\hline Week 8 & $-3.1(-17.4,11.3), 48$ & $-10.1(-25.3,5.0), 34$ \\
\hline Week 16 & $-11.4(-28.5,5.6), 26$ & $-0.1(-17.8,17.5), 16$ \\
\hline Month 6 & $3.0(-17.8,23.9), 25$ & $-5.4(-29.2,18.4), 18$ \\
\hline \multicolumn{3}{|l|}{ Social functioning } \\
\hline Week 8 & $-8.3(-22.0,5.4), 47$ & $0.4(-14.8,15.7), 34$ \\
\hline Week 16 & $-11.4(-25.3,2.6), 26$ & $-2.4(-23.9,19.1), 16$ \\
\hline Month 6 & $-2.2(-20.7,16.3), 25$ & $14.4(-12.0,40.7), 18$ \\
\hline
\end{tabular}

Bold indicates clinically relevant. Analyses of change from baseline were based on a Kruskal-

Wallis test including treatment as the sole factor.

CCNU, lomustine; CI, confidence interval; Depatux-M, depatuxizumab mafodotin; QLQ-C30,

European Organization for Research and Treatment of Cancer Quality of Life Questionnaire;

TMZ, temozolomide. 
Self-reported visual disorders were mostly impacted by treatment with Depatux-M relative to TMZ/CCNU (Table 4, Fig. 2, and Supplementary Table 4). Both Depatux-M arms reported an increase from baseline in self-reported visual disorders that was clinically relevant compared with TMZ/CCNU at all time points (difference range 24.6-35.1) (Table 4, Fig. 2, and Supplementary Table 4). The effect was greatest at Week 8 and remained clinically relevant at all other time points. 
Table 4. Change from baseline with Depatux-M relative to TMZ/CCNU in QLQ-BN20 scale scores

\begin{tabular}{|c|c|c|}
\hline $\begin{array}{l}\text { Difference from TMZ/CCNU, } \\
\text { mean }(95 \% \mathrm{CI}), \mathrm{n}\end{array}$ & $\begin{array}{c}\text { Depatux-M + TMZ } \\
(\mathrm{n}=88)\end{array}$ & $\begin{array}{c}\text { Depatux-M } \\
(\mathbf{n}=86)\end{array}$ \\
\hline \multicolumn{3}{|l|}{ Bladder control } \\
\hline Week 8 & $4.5(-4.1,13.1), 48$ & $6.0(-5.6,17.6), 33$ \\
\hline Week 16 & $7.5(-7.9,22.9), 26$ & $2.4(-8.6,13.4), 15$ \\
\hline Month 6 & $-4.9(-24.7,14.9), 25$ & $-10.7(-28.8,7.3), 18$ \\
\hline \multicolumn{3}{|l|}{ Communication deficit } \\
\hline Week 8 & $4.6(-3.0,12.2), 48$ & $5.8(-4.6,16.2), 33$ \\
\hline Week 16 & $8.1(-2.2,18.4), 26$ & $-0.7(-16.3,14.9), 15$ \\
\hline Month 6 & $5.4(-9.7,20.6), 24$ & $-7.2(-23.1,8.8), 18$ \\
\hline \multicolumn{3}{|l|}{ Drowsiness } \\
\hline Week 8 & $1.0(-12.1,14.0), 46$ & $3.9(-10.3,18.0), 33$ \\
\hline Week 16 & $0.9(-13.9,15.7), 26$ & $-0.8(-24.8,23.2), 15$ \\
\hline Month 6 & $1.9(-17.6,21.4), 25$ & $10.1(-11.1,31.2), 18$ \\
\hline \multicolumn{3}{|l|}{ Future uncertainty } \\
\hline Week 8 & $3.0(-8.8,14.8), 48$ & $6.9(-6.3,20.1), 33$ \\
\hline Week 16 & $-1.0(-13.6,11.6), 26$ & $0.0(-17.1,17.2), 15$ \\
\hline Month 6 & $-0.9(-17.2,15.4), 25$ & $-4.4(-22.8,14.1), 18$ \\
\hline \multicolumn{3}{|l|}{ Hair loss } \\
\hline Week 8 & $-7.2(-16.2,1.7), 46$ & $-10.2(-18.7,-1.8), 33$ \\
\hline Week 16 & $-6.4(-19.8,7.1), 25$ & $-9.0(-24.1,6.0), 15$ \\
\hline Month 6 & $2.2(-10.9,15.3), 23$ & $-1.5(-11.1,8.2), 18$ \\
\hline \multicolumn{3}{|l|}{ Headaches } \\
\hline Week 8 & $-8.0(-18.8,2.7), 47$ & $-3.2(-15.7,9.3), 33$ \\
\hline Week 16 & $4.8(-12.4,21.9), 25$ & $13.7(-\mathbf{2 . 8}, \mathbf{3 0 . 1}), 15$ \\
\hline Month 6 & $2.4(-13.5,18.3), 23$ & $0.5(-15.6,16.7), 18$ \\
\hline \multicolumn{3}{|l|}{ Itchy skin } \\
\hline Week 8 & $1.3(-7.4,10.0), 48$ & $-6.2(-16.7,4.3), 33$ \\
\hline Week 16 & $-4.2(-24.5,16.1), 26$ & $-11.9(-33.6,9.8), 15$ \\
\hline Month 6 & $-2.1(-21.6,17.4), 25$ & $-4.8(-28.7,19.2), 18$ \\
\hline \multicolumn{3}{|l|}{ Motor dysfunction } \\
\hline Week 8 & $-6.6(-16.2,3.0), 47$ & $-8.2(-19.2,2.7), 33$ \\
\hline Week 16 & $-4.6(-17.8,8.6), 26$ & $0.7(-17.0,18.3), 15$ \\
\hline Month 6 & $-10.6(-27.3,6.2), 24$ & $-0.4(-20.8,20.1), 18$ \\
\hline \multicolumn{3}{|l|}{ Seizures } \\
\hline Week 8 & $-7.1(-17.9,3.6), 48$ & $1.0(-12.1,14.2), 33$ \\
\hline Week 16 & $-3.5(-14.5,7.5), 26$ & $-7.1(-18.3,4.0), 14$ \\
\hline Month 6 & $-5.0(-12.2,2.2), 24$ & $-9.6(-19.6,0.4), 18$ \\
\hline \multicolumn{3}{|l|}{ Visual disorder } \\
\hline Week 8 & $35.1(26.7,43.6), 48$ & $34.5(23.4,45.6), 33$ \\
\hline Week 16 & $26.9(14.2,39.5), 26$ & $30.0(11.7,48.4), 15$ \\
\hline Month 6 & $25.2(\mathbf{1 0 . 8}, \mathbf{3 9 . 6}), 24$ & $24.6(10.1,39.0), 18$ \\
\hline
\end{tabular}


Weakness in legs

Week 8

Week 16

$$
\begin{array}{ll}
-5.1(-18.4,8.3), 47 & -7.6(-21.1,5.9), 33 \\
-6.3(-26.3,13.7), 25 & -9.8(-37.0,17.3), 15
\end{array}
$$

Month 6

$-4.7(-27.2,17.8), 24 \quad 9.6(-17.4,36.6), 18$

Bold indicates clinically relevant. Analyses of change from baseline were based on a Kruskal-

Wallis test including treatment as the sole factor.

CCNU, lomustine; CI, confidence interval; Depatux-M, depatuxizumab mafodotin; QLQ-BN20, European Organization for Research and Treatment of Cancer Quality of Life Questionnaire Brain Cancer Module; TMZ, temozolomide.

Fig. 2. Change from baseline in visual disorder scale score in the three treatment arms

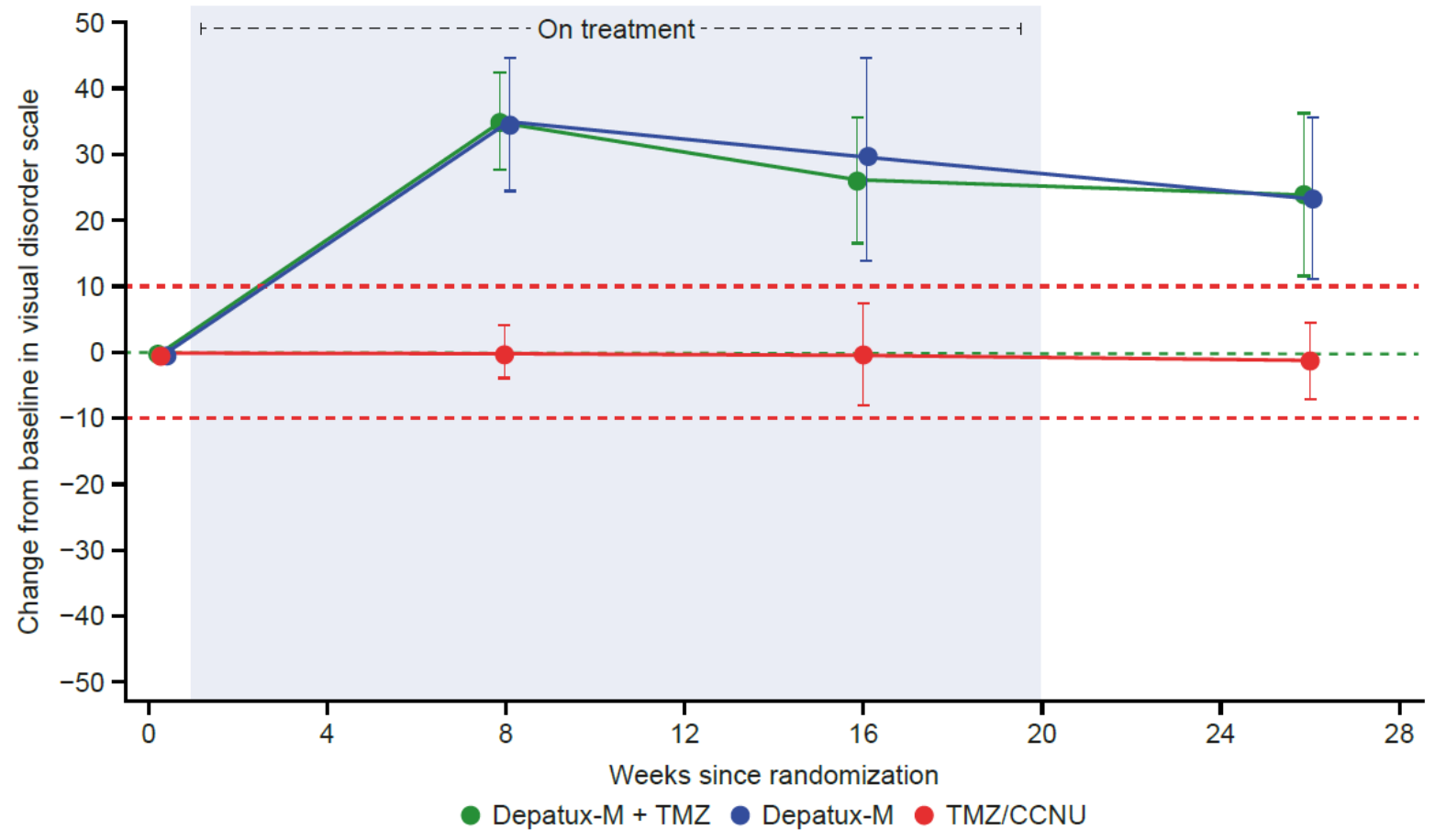

Number of patients observed

$\begin{array}{lcccc} & \text { Baseline } & \text { Week } 8 & \text { Week } 16 & \text { Month } 6 \\ \text { DepatuX-M + TMZ } & 78 & 48 & 26 & 24 \\ \text { DepatuX-M } & 69 & 33 & 15 & 18 \\ \text { TMZ/CCNU } & 77 & 33 & 14 & 15\end{array}$

CCNU, lomustine; Depatux-M, depatuxizumab mafodotin; TMZ, temozolomide.

Error bars represent $95 \%$ confidence intervals. 
Grade 3/4 ocular toxicity (Supplementary Table 5) was reported by 45 patients receiving Depatux-M, with the majority grade $3(96 \%, n=43)$. Grade $3 / 4$ ocular toxicity resolved to grade 2 or lower for $73 \%(n=33)$ of patients, with $81.8 \%(n=27)$ resolving before Depatux-M discontinuation and $18.2 \%(n=6)$ after discontinuation.

Visual disorder was the only HRQoL scale showing a consistent and considerable deterioration across Depatux treatment arms. Other clinically relevant changes in symptoms, as measured with the HRQoL questionnaires, relative to baseline for both Depatux-M treatment arms vs. the TMZ/CCNU treatment arm were increase in appetite loss (Week 8) and diarrhea (Week 16), and change in insomnia (Week 16, decrease with Depatux-M plus TMZ and increase with DepatuxM) (Table 5 and Supplementary Table 6). Clinically relevant reductions in pain and constipation were reported at Week 16 and Month 6 with Depatux-M (but not Depatux-M plus TMZ) vs. TMZ/CCNU relative to baseline (Table 5 and Supplementary Table 6). Several other clinically relevant changes relative to baseline were observed for only one of the Depatux-M treatment arms vs. the TMZ/CCNU and at only one time point (Table 4). 
Table 5. Change from baseline with Depatux-M relative to TMZ/CCNU in QLQ-C30

symptom responses

\begin{tabular}{|c|c|c|}
\hline $\begin{array}{l}\text { Difference from TMZ/CCNU, } \\
\text { mean }(95 \% \text { CI), } n\end{array}$ & $\begin{array}{c}\text { Depatux-M + TMZ } \\
(\mathrm{n}=88)\end{array}$ & $\begin{array}{c}\text { Depatux-M } \\
(\mathrm{n}=86)\end{array}$ \\
\hline \multicolumn{3}{|l|}{ Appetite loss } \\
\hline Week 8 & $13.8(\mathbf{0 . 6}, \mathbf{2 7 . 0}), 48$ & $11.1(-\mathbf{3 . 8}, \mathbf{2 6 . 0}), 33$ \\
\hline Week 16 & $1.2(-12.4,14.9), 27$ & $6.3(-12.4,24.9), 16$ \\
\hline Month 6 & $5.2(-11.7,22.0), 25$ & $-4.2(-18.8,10.4), 17$ \\
\hline \multicolumn{3}{|l|}{ Constipation } \\
\hline Week 8 & $8.8(-2.7,20.4), 48$ & $-9.0(-19.6,1.7), 34$ \\
\hline Week 16 & $2.9(-13.0,18.8), 27$ & $-14.0(-29.2,1.2), 16$ \\
\hline Month 6 & $2.9(-15.1,21.3), 25$ & $-21.5(-37.8,-5.3), 18$ \\
\hline \multicolumn{3}{|l|}{ Diarrhea } \\
\hline Week 8 & $5.9(-3.2,15.1), 46$ & $7.0(-3.1,17.0), 34$ \\
\hline Week 16 & $13.2(-9.1,35.4), 26$ & $16.1(-7.3,39.4), 16$ \\
\hline Month 6 & $1.9(-14.9,18.7), 25$ & $-0.2(-16.5,16.0), 18$ \\
\hline \multicolumn{3}{|l|}{ Dyspnea } \\
\hline Week 8 & $-2.1(-12.1,7.9), 47$ & $0.9(-13.0,14.7), 34$ \\
\hline Week 16 & $-2.6(-18.3,13.2), 26$ & $0.0(-18.0,18.0), 16$ \\
\hline Month 6 & $0.7(-12.6,14.0), 24$ & $-6.0(-21.1,9.1), 17$ \\
\hline \multicolumn{3}{|l|}{ Fatigue } \\
\hline Week 8 & $-4.7(-16.0,6.5), 48$ & $-2.1(-14.1,9.8), 34$ \\
\hline Week 16 & $2.3(-10.6,15.2), 27$ & $-3.7(-19.9,12.5), 16$ \\
\hline Month 6 & $-0.8(-18.9,17.4), 25$ & $-2.7(-23.6,18.1), 18$ \\
\hline \multicolumn{3}{|l|}{ Insomnia } \\
\hline Week 8 & $-8.8(-22.9,5.3), 47$ & $-2.1(-17.6,13.3), 34$ \\
\hline Week 16 & $-13.5(-30.6,3.6), 27$ & $10.1(-7.7,27.9), 16$ \\
\hline Month 6 & $-4.0(-20.7,12.7), 25$ & $-1.9(-20.5,16.8), 18$ \\
\hline \multicolumn{3}{|l|}{ Nausea/vomiting } \\
\hline Week 8 & $2.8(-3.6,9.2), 48$ & $0.0(-5.0,5.0), 34$ \\
\hline Week 16 & $1.3(-11.2,13.7), 27$ & $0.9(-12.5,14.2), 16$ \\
\hline Month 6 & $7.7(0.6,14.8), 25$ & $-1.7(-8.7,5.2), 18$ \\
\hline \multicolumn{3}{|l|}{ Pain } \\
\hline Week 8 & $0.3(-10.7,11.4), 48$ & $-1.1(-14.8,12.6), 34$ \\
\hline Week 16 & $-9.4(-24.2,5.3), 27$ & $-14.0(-32.0,4.0), 16$ \\
\hline Month 6 & $6.1(-9.9,22.1), 25$ & $-10.8(-27.8,6.2), 18$ \\
\hline
\end{tabular}

Bold indicates clinically relevant. Analyses of change from baseline were based on a Kruskal-

Wallis test including treatment as the sole factor. 
CCNU, lomustine; CI, confidence interval; Depatux-M, depatuxizumab mafodotin; QLQ-C30, European Organization for Research and Treatment of Cancer Quality of Life Questionnaire; TMZ, temozolomide. 


\subsection{Impact of Depatux-M on NDFS}

Analysis of NDFS did not show a statistically significant difference between Depatux-M treatment arms and TMZ/CCNU (Fig. 3 and Supplementary Table 7); median NDFS were 5.98, 5.52, and 6.08 months for the Depatux-M plus TMZ, Depatux-M alone and TMZ/CCNU arms respectively. The hazard ratio $(95 \% \mathrm{CI}$; $P$-value) for Depatux-M plus TMZ and Depatux-M vs. TMZ/CCNU was $0.77(0.55-1.09 ; 0.137)$ and $1.04(0.74-1.48 ; 0.818)$ (Supplementary

\section{Table 7).}


Fig. 3. Kaplan-Meier plot of neurological deterioration-free survival with Depatux-M plus TMZ versus TMZ/CCNU (A) and Depatux-M versus TMZ/CCNU (B)

A
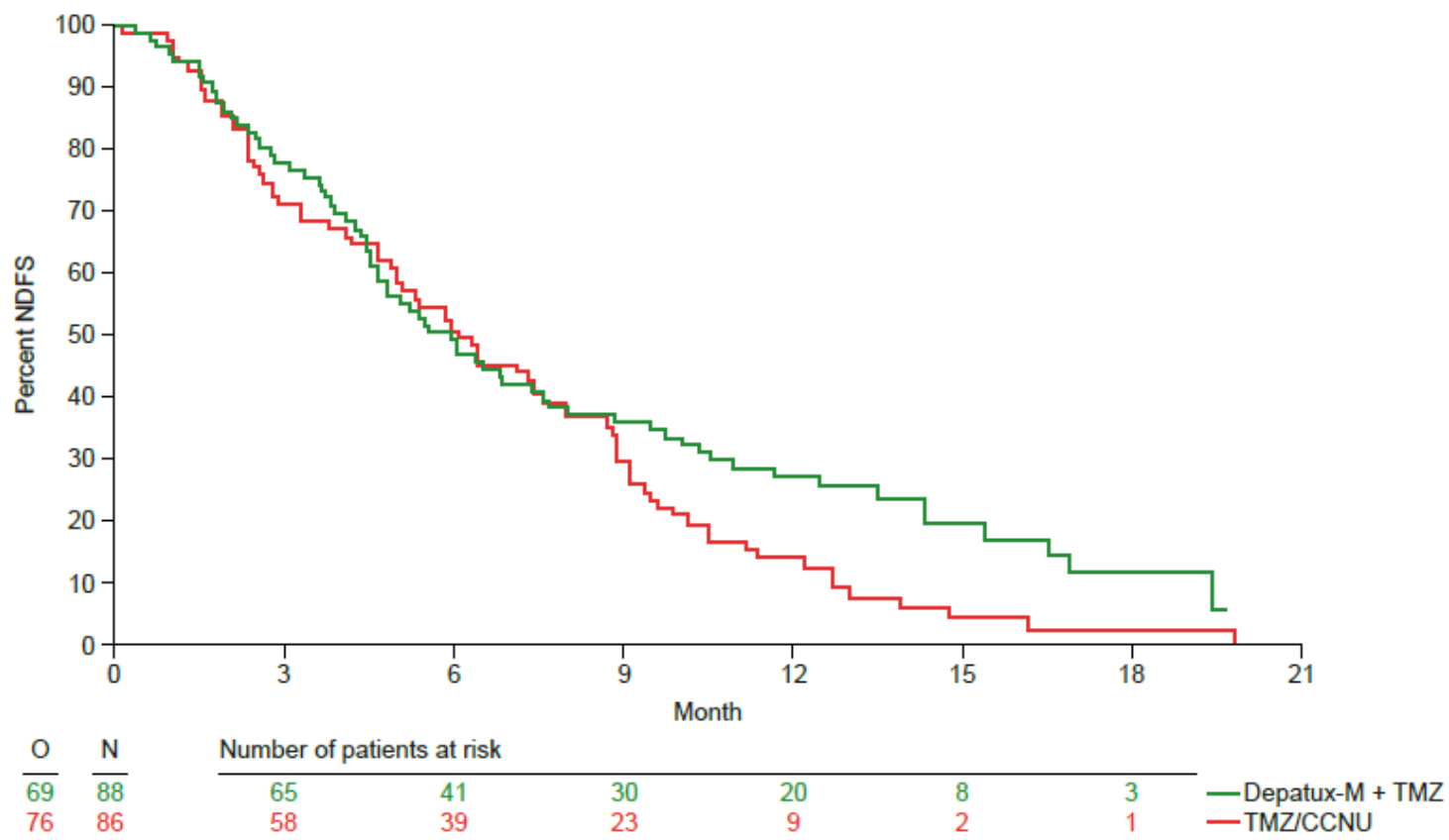

B

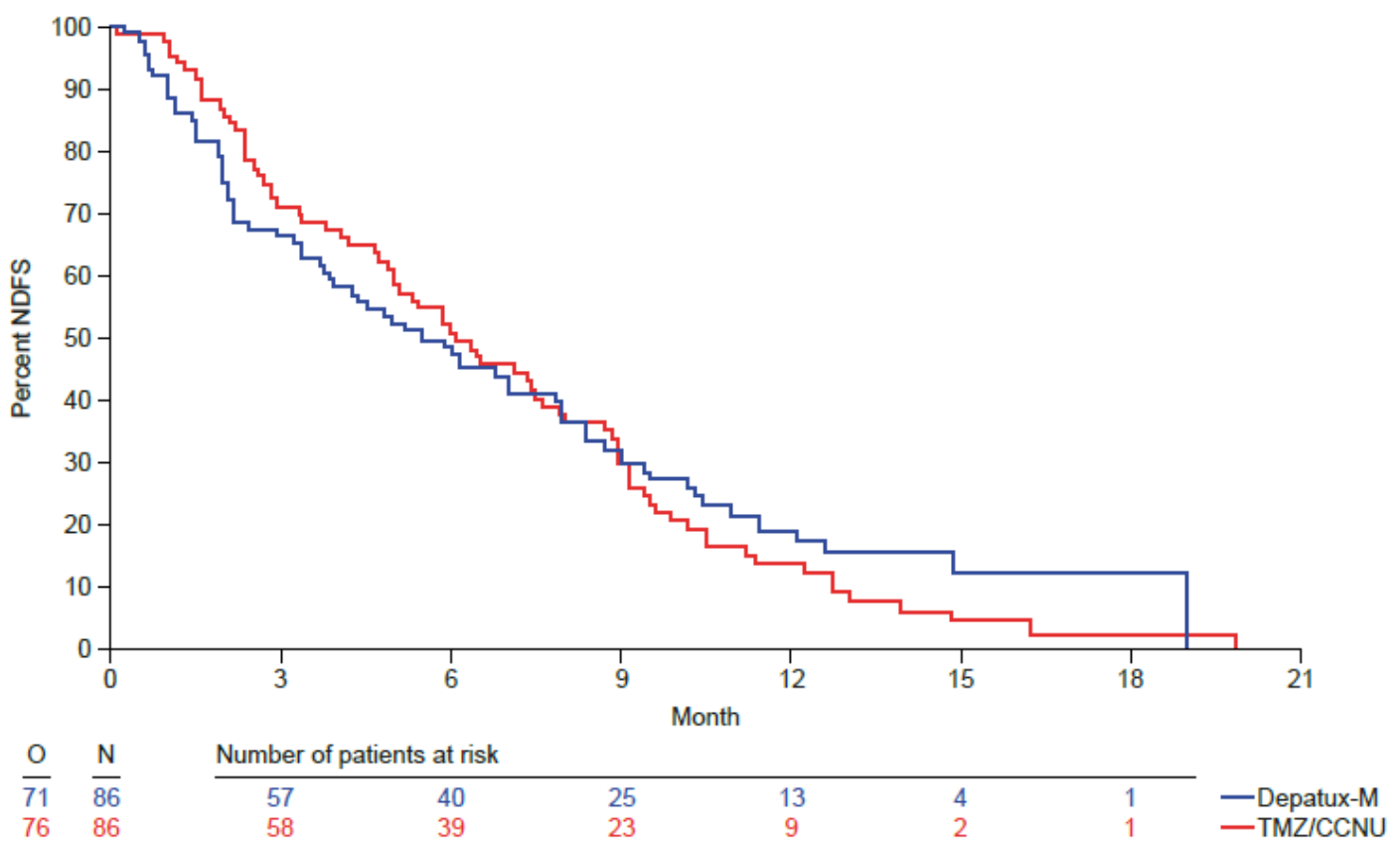

CCNU, lomustine; Depatux-M, depatuxizumab mafodotin; NDFS, neurological deteriorationfree survival; TMZ, temozolomide. 


\section{Discussion}

Patients with recurrent glioblastoma experience serious HRQoL issues related to both their disease and its associated treatment, which is also apparent in the current study [5, 33-36]. Depatux-M, an antibody-drug conjugate that targets cells with amplified EGFR, demonstrated promising survival data in early clinical trials for the treatment of glioblastoma, but at the cost of associated adverse events, particularly a dose-limiting ocular toxicity. In view of this, it was important to understand the effect of this drug on patients' HRQoL aspects [23-27]. We observed no substantial, long-lasting changes from baseline in the global health/QoL status for patients receiving Depatux-M, either alone or in combination with TMZ, compared with TMZ/CCNU. The decrease in global health/QoL status observed at Week 8 for all three arms, which was clinically relevant for Depatux-M monotherapy, was transient as it improved at Week 16 and remained stable thereafter. It should be noted though, that patient attrition and decreasing compliance with HRQoL assessments over time, may have caused an overrepresentation of patients in better condition at later visits, and subsequently an overestimation of HRQoL scores during follow-up.[37]

The clinically relevant worsening in self-reported visual disorders in patients treated with Depatux-M at all time points corroborates previously reported toxicity data [23-26]. Ocular toxicity was the clinically most relevant toxicity in this study, with $32.9 \%$ and $23.8 \%$ of patients reporting grade 3 or 4 ocular toxicity in the Depatux-M plus TMZ and Depatux-M arms, respectively [27]. Discontinuation due to ocular toxicity occurred in $3.4 \%(n=3 / 88)$ and $4.7 \%$ $(n=4 / 86)$ of patients receiving Depatux-M plus TMZ and Depatux-M, respectively. As ocular toxicity can occur with a median time to onset of approximately 3 weeks [23], the higher level of 
self-reported visual disorders at Week 8 may reflect a greater proportion of patients sensitive to the side effects of the drug, who withdrew from the study and were not evaluated at later time points [27]. More likely, dose delays and dose reduction may have contributed to the better tolerability at later time points, as only $7 \%$ of all Depatux-M treated patients discontinued treatment for toxicity [27]. The clinically relevant decrease in cognitive functioning at Week 8 with Depatux-M relative to TMZ/CCNU may also be related to ocular toxicity. Cognitive functioning as measured with EORTC QLQ-C30 comprises the domains memory and concentration, with the latter referring to activities such as reading and watching television, which may be compromised by visual problems.

The clinically relevant reduction in constipation at Week 16 and Month 6 with Depatux-M monotherapy compared with TMZ/CCNU may potentially be due to adverse events associated with TMZ or the associated antiemetics that are used [38]. Other clinically relevant observations that occurred once and with only one Depatux-M treatment regimen may be due to reproducibility issues associated with the low number of patients because of attrition (and thus hampering statistical reliability).

An observed long-term benefit of Depatux-M plus TMZ, but not Depatux-M treatment alone vs. TMZ/CCNU on NDFS is consistent with what has been observed for overall survival, which is part of the definition of NDFS [27]. Although not significant, Depatux-M plus TMZ provided an overall survival benefit over TMZ/CCNU (hazard ratio: $0.71 ; 95 \% \mathrm{CI}: 0.50-1.02 ; P=0.06$ ). No overall survival benefit was observed with Depatux-M monotherapy (hazard ratio: 1.04; 95\% CI: $0.73-1.48 ; P=0.83)[27]$. 
Certain limitations were associated with this study. As this was a trial population, findings from this study are not generalizable to the whole patient population with recurrent glioblastoma. As both HRQoL and NDFS were exploratory endpoints, there was no formal hypothesis formulated or underlying power calculation. The predefined HRQoL categorization was based on an established notion of a 10-point difference at the time of the study conception. However, more recent publications $[39,40]$ have argued that smaller differences could be considered clinically relevant as well, although there is no clear consensus yet. Decreasing compliance and attrition over time introduced uncertainty due to low numbers and potential bias due to patient selection. Ideally, the conclusion on the impact of treatment on HRQoL should be based on both statistically significant and clinically relevant differences. Although theoretically addressed by randomization, the potential of confounding factors influencing the HRQoL results cannot be excluded. 


\section{Conclusions}

The global health/QoL status reported here did not differ substantially between treatment groups. A transient deterioration of HRQoL was noted in the entire population, before the scores returned to baseline values. The greater frequency of self-reported visual disorders with Depatux-M compared with TMZ/CCNU demonstrates the clinically significant ocular toxicity of Depatux-M. This analysis shows the value of HRQoL questionnaires in the assessment of treatment regimens and their impact on safety and introduces NDFS as a new concept to evaluate clinical outcome. 


\section{Declaration of Interest statement}

Linda Dirven, Sarah Nuyens, Maarten Spruyt, Thierry Gorlia, Corneel Coens, and Jaap C. Reijneveld have nothing to disclose. Paul M. J. Clement received study budget funds from AstraZeneca; was an advisory board member for AbbVie, AstraZeneca, BMS, Daiichi-Sankyo, Leo Pharma, Merck Serono, MSD, and Vifor Pharma. Marica Eoli received consulting fees from AbbVie. Juan M. Sepulveda-Sanchez reports personal fees and non-financial support from AbbVie; a grant from Pfizer as principal investigator; personal fees and non-financial support from Celgene; non-financial support from Ipsen; and personal fees from Astellas. Annemiek M. E. Walenkamp received research grants from IPSEN and Novartis; was an advisory board member for IPSEN, Karyopharm, Novartis, and Polyphor; and received study budget funds from AbbVie, BMS, Genzyme, Karyopharm Therapeutics, and Roche. Jean Sebastien Frenel has received consulting fees from AstraZeneca, BIOCAD, Lilly, Novartis, Pfizer, and Roche. Enrico Franceschi was an advisory board member for Celgene and Karyopharm. Michael Weller has received research grants from AbbVie, Adastra, Merck, Sharp \& Dohme (MSD), Merck (EMD), and Novocure; and honoraria for lectures or advisory board participation or consulting from AbbVie, Basilea, Bristol Myers Squibb (BMS), Celgene, Medac, Merck, Sharp \& Dohme (MSD), Merck (EMD), Nerviano Medical Sciences, Novartis, Orbus, Philogen, Roche, and Tocagen. Olivier Chinot reports personal fees and non-financial support from Abbvie, during the conduct of the study; personal fees from immatics, non-financial support from BMS, nonfinancial support from Servier, grants, personal fees and non-financial support from Roche, outside the submitted work. Filip Y. F. L. De Vos received research grants from Novartis. Nicholas Whenham has received consulting fees from Bayer and Janssen. Paul Sanghera was an advisory board member for AbbVie and Roche. Jim Looman, Madan G. Kundu, and Jan Peter de 
Geus are AbbVie employees and may own stock. Vassilis Golfinopoulos received research funding from AbbVie during the conduct of the study. Martin J. van den Bent received consulting fees from AbbVie, Agios, Bayer, Boston Pharmaceuticals, Carthera, Genenta, Karyopharm, and Nerviano. 


\section{References}

[1] Ostrom QT, Gittleman H, Liao P, Vecchione-Koval T, Wolinsky Y, Kruchko C, et al. CBTRUS Statistical Report: Primary brain and other central nervous system tumors diagnosed in the United States in 2010-2014. Neuro Oncol. 2017;19:v1-v88.

[2] GBD 2016 Brain and Other CNS Cancer Collaborators. Global, regional, and national burden of brain and other CNS cancer, 1990-2016: a systematic analysis for the Global Burden of Disease Study 2016. Lancet Neurol. 2019;18:376-93.

[3] Ostrom QT, Gittleman H, de Blank PM, Finlay JL, Gurney JG, McKean-Cowdin R, et al. American Brain Tumor Association adolescent and young adult primary brain and central nervous system tumors diagnosed in the United States in 2008-2012. Neuro Oncol. 2016;18 Suppl 1:i1-i50.

[4] Sterckx W, Coolbrandt A, Dierckx de Casterle B, Van den Heede K, Decruyenaere M, Borgenon S, et al. The impact of a high-grade glioma on everyday life: a systematic review from the patient's and caregiver's perspective. Eur J Oncol Nurs. 2013;17:107-17.

[5] Taphoorn MJ, Claassens L, Aaronson NK, Coens C, Mauer M, Osoba D, et al. An international validation study of the EORTC brain cancer module (EORTC QLQ-BN20) for assessing health-related quality of life and symptoms in brain cancer patients. Eur J Cancer. 2010;46:1033-40.

[6] National Comprehensive Cancer Network. NCCN clinical practice guidelines in oncology (NCCN guidelines ${ }^{\circledR}$ ). Central nervous system cancers. 2019. Available from: https://www.nccn.org/store/login/login.aspx?ReturnURL=https://www.nccn.org/professionals/ph ysician_gls/pdf/cns.pdf [Accessed April 16, 2019]. 
[7] Weller M, van den Bent M, Tonn JC, Stupp R, Preusser M, Cohen-Jonathan-Moyal E, et al. European Association for Neuro-Oncology (EANO) guideline on the diagnosis and treatment of adult astrocytic and oligodendroglial gliomas. Lancet Oncol. 2017;18:e315-e29.

[8] Brennan CW, Verhaak RG, McKenna A, Campos B, Noushmehr H, Salama SR, et al. The somatic genomic landscape of glioblastoma. Cell. 2013;155:462-77.

[9] Gan HK, Cvrljevic AN, Johns TG. The epidermal growth factor receptor variant III (EGFRvIII): where wild things are altered. FEBS J. 2013;280:5350-70.

[10] Yoshimoto K, Dang J, Zhu S, Nathanson D, Huang T, Dumont R, et al. Development of a real-time RT-PCR assay for detecting EGFRvIII in glioblastoma samples. Clin Cancer Res. 2008;14:488-93.

[11] Van den Bent MJ, Roberts-Rapp LA, Ansell P, Lee J, Looman J, Bain E, et al. Epidermal growth factor receptor (EGFR) amplification rates observed in screening patients for randomized clinical trials in glioblastoma. Ann Oncol. 2017;28(suppl_5).

[12] van den Bent MJ, Gao Y, Kerkhof M, Kros JM, Gorlia T, van Zwieten K, et al. Changes in the EGFR amplification and EGFRvIII expression between paired primary and recurrent glioblastomas. Neuro Oncol. 2015;17:935-41.

[13] Felsberg J, Hentschel B, Kaulich K, Gramatzki D, Zacher A, Malzkorn B, et al. Epidermal growth factor receptor variant III (EGFRvIII) positivity in EGFR-amplified glioblastomas: prognostic role and comparison between primary and recurrent tumors. Clin Cancer Res. 2017;23:6846-55.

[14] van den Bent MJ, Brandes AA, Rampling R, Kouwenhoven MC, Kros JM, Carpentier AF, et al. Randomized phase II trial of erlotinib versus temozolomide or carmustine in recurrent glioblastoma: EORTC brain tumor group study 26034. J Clin Oncol. 2009;27:1268-74. 
[15] Sepulveda-Sanchez JM, Vaz MA, Balana C, Gil-Gil M, Reynes G, Gallego O, et al. Phase II trial of dacomitinib, a pan-human EGFR tyrosine kinase inhibitor, in recurrent glioblastoma patients with EGFR amplification. Neuro Oncol. 2017;19:1522-31.

[16] Kreisl TN, Lassman AB, Mischel PS, Rosen N, Scher HI, Teruya-Feldstein J, et al. A pilot study of everolimus and gefitinib in the treatment of recurrent glioblastoma (GBM). J

Neurooncol. 2009;92:99-105.

[17] Raizer JJ, Abrey LE, Lassman AB, Chang SM, Lamborn KR, Kuhn JG, et al. A phase II trial of erlotinib in patients with recurrent malignant gliomas and nonprogressive glioblastoma multiforme postradiation therapy. Neuro Oncol. 2010;12:95-103.

[18] Peereboom DM, Shepard DR, Ahluwalia MS, Brewer CJ, Agarwal N, Stevens GH, et al. Phase II trial of erlotinib with temozolomide and radiation in patients with newly diagnosed glioblastoma multiforme. J Neurooncol. 2010;98:93-9.

[19] Raizer JJ, Giglio P, Hu J, Groves M, Merrell R, Conrad C, et al. A phase II study of bevacizumab and erlotinib after radiation and temozolomide in MGMT unmethylated GBM patients. J Neurooncol. 2016;126:185-92.

[20] Chakravarti A, Wang M, Robins HI, Lautenschlaeger T, Curran WJ, Brachman DG, et al. RTOG 0211: a phase 1/2 study of radiation therapy with concurrent gefitinib for newly diagnosed glioblastoma patients. Int J Radiat Oncol Biol Phys. 2013;85:1206-11.

[21] Neyns B, Sadones J, Joosens E, Bouttens F, Verbeke L, Baurain JF, et al. Stratified phase II trial of cetuximab in patients with recurrent high-grade glioma. Ann Oncol. 2009;20:1596-603. [22] Phillips AC, Boghaert ER, Vaidya KS, Mitten MJ, Norvell S, Falls HD, et al. ABT-414, an antibody-drug conjugate targeting a tumor-selective EGFR epitope. Mol Cancer Ther. 2016;15:661-9. 
[23] van den Bent M, Gan HK, Lassman AB, Kumthekar P, Merrell R, Butowski N, et al. Efficacy of depatuxizumab mafodotin (ABT-414) monotherapy in patients with EGFRamplified, recurrent glioblastoma: results from a multi-center, international study. Cancer Chemother Pharmacol. 2017;80:1209-17.

[24] Reardon DA, Lassman AB, van den Bent M, Kumthekar P, Merrell R, Scott AM, et al. Efficacy and safety results of ABT-414 in combination with radiation and temozolomide in newly diagnosed glioblastoma. Neuro Oncol. 2017;19:965-75.

[25] Gan HK, Reardon DA, Lassman AB, Merrell R, van den Bent M, Butowski N, et al. Safety, pharmacokinetics, and antitumor response of depatuxizumab mafodotin as monotherapy or in combination with temozolomide in patients with glioblastoma. Neuro Oncol. 2018;20:838-47. [26] Lassman AB, van den Bent MJ, Gan HK, Reardon DA, Kumthekar P, Butowski N, et al. Safety and efficacy of depatuxizumab mafodotin + temozolomide in patients with EGFRamplified, recurrent glioblastoma: results from an international phase I multicenter trial. Neuro Oncol. 2019;21:106-14.

[27] Van Den Bent M, Eoli M, Sepulveda JM, Smits M, Walenkamp A, Frenel JS, et al. INTELLANCE 2/EORTC 1410 randomized phase II study of Depatux-M alone and with temozolomide vs temozolomide or lomustine in recurrent EGFR amplified glioblastoma. Neuro Oncol. 2020;22:684-93.

[28] Aaronson NK, Ahmedzai S, Bergman B, Bullinger M, Cull A, Duez NJ, et al. The European Organization for Research and Treatment of Cancer QLQ-C30: a quality-of-life instrument for use in international clinical trials in oncology. J Natl Cancer Inst. 1993;85:365-76. 
[29] Fayers P, Aaronson NK, Bjordal K, Groenvold M, Curran D, Bottomley A. EORTC QLQC30 Scoring Manual. 2001. Available from:

https://www.eortc.org/app/uploads/sites/2/2018/02/SCmanual.pdf [Accessed June 23, 2020].

[30] Kulis D, Bottomley A, Velikova G, Greimel E, Koller M, on behalf of the EORTC Quality of Life Group. EORTC quality of life group translation procedure. 2017;4th edition. Available from: https://www.eortc.org/app/uploads/sites/2/2018/02/translation_manual_2017.pdf [Accessed July 5, 2019].

[31] Osoba D, Rodrigues G, Myles J, Zee B, Pater J. Interpreting the significance of changes in health-related quality-of-life scores. J Clin Oncol. 1998;16:139-44.

[32] Kruskal WH, Wallis WA. Use of ranks in one-criterion variance analysis. J Am Stat Assoc. 1952;47:583-621.

[33] Gabel N, Altshuler DB, Brezzell A, Briceno EM, Boileau NR, Miklja Z, et al. Health related quality of life in adult low and high-grade glioma patients using the National Institutes of Health Patient Reported Outcomes Measurement Information System (PROMIS) and Neuro-QOL assessments. Front Neurol. 2019;10:212.

[34] Taphoorn MJ, Henriksson R, Bottomley A, Cloughesy T, Wick W, Mason WP, et al. Health-related quality of life in a randomized phase III study of bevacizumab, temozolomide, and radiotherapy in newly diagnosed glioblastoma. J Clin Oncol. 2015;33:2166-75.

[35] Bitterlich C, Vordermark D. Analysis of health-related quality of life in patients with brain tumors prior and subsequent to radiotherapy. Oncol Lett. 2017;14:1841-6.

[36] Flechl B, Sax C, Ackerl M, Crevenna R, Woehrer A, Hainfellner J, et al. The course of quality of life and neurocognition in newly diagnosed patients with glioblastoma. Radiother Oncol. 2017;125:228-33. 
[37] Dirven L, Reijneveld JC, Aaronson NK, Bottomley A, Uitdehaag BM, Taphoorn MJ. Health-related quality of life in patients with brain tumors: limitations and additional outcome measures. Curr Neurol Neurosci Rep. 2013;13:359.

[38] Agarwala SS, Kirkwood JM. Temozolomide, a novel alkylating agent with activity in the central nervous system, may improve the treatment of advanced metastatic melanoma.

Oncologist. 2000;5:144-51.

[39] Cocks K, King MT, Velikova G, de Castro G, Jr., Martyn St-James M, Fayers PM, et al. Evidence-based guidelines for interpreting change scores for the European Organisation for the Research and Treatment of Cancer Quality of Life Questionnaire Core 30. Eur J Cancer. 2012;48:1713-21.

[40] Wong E, Zhang L, Kerba M, Arnalot PF, Danielson B, Tsao M, et al. Minimal clinically important differences in the EORTC QLQ-BN20 in patients with brain metastases. Support Care Cancer. 2015;23:2731-7. 
'Click here to acces $\$$ /dogunload;Figure;ABB [2276] Figure 1.eps $\stackrel{ \pm}{\underline{N}}$

\section{.}

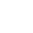

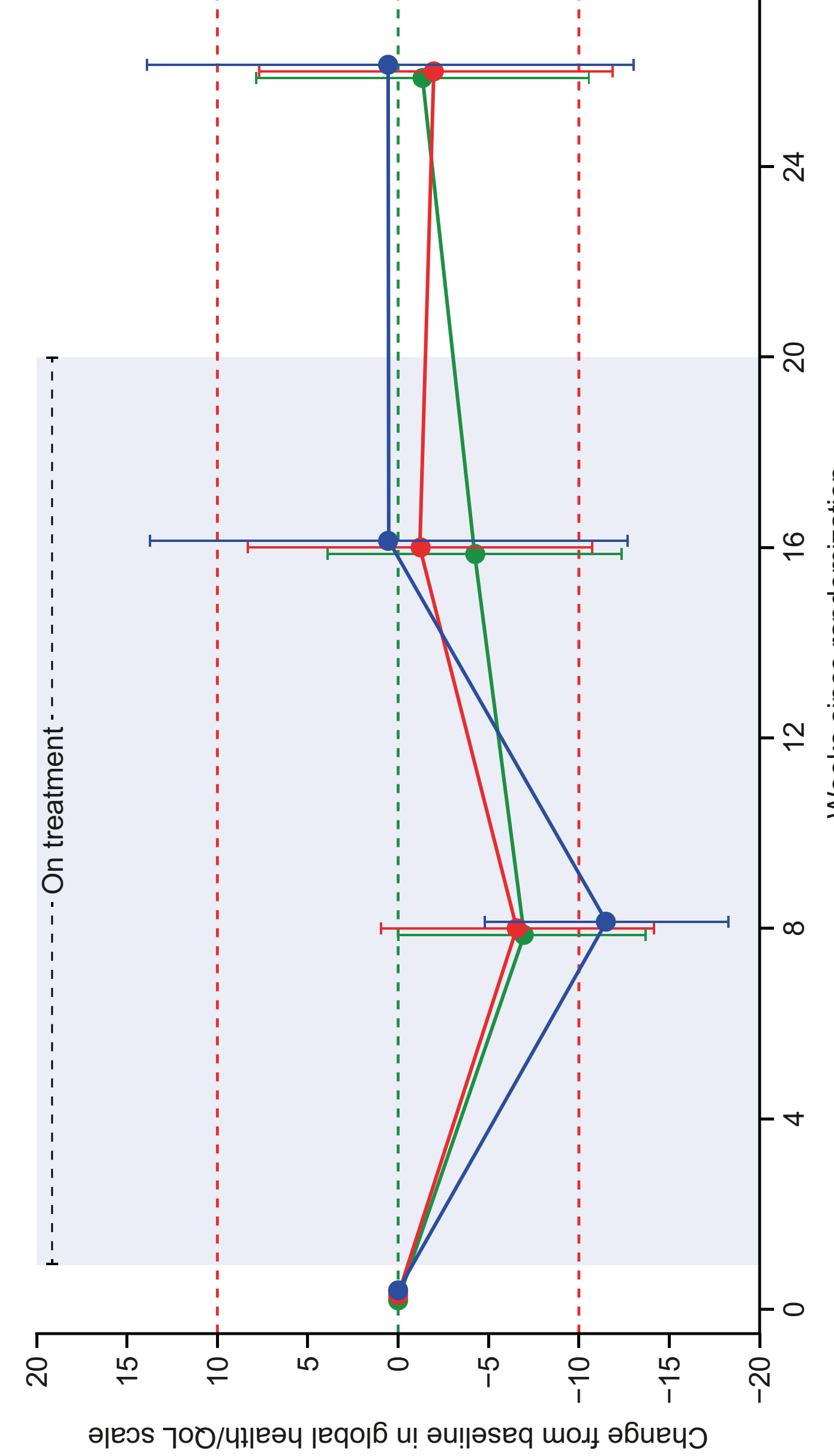

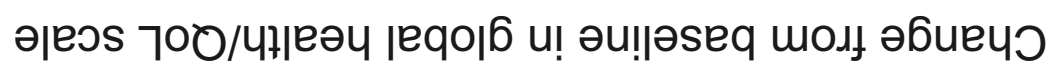

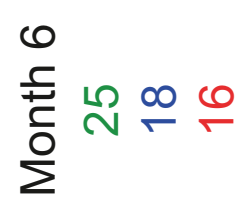

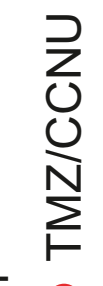

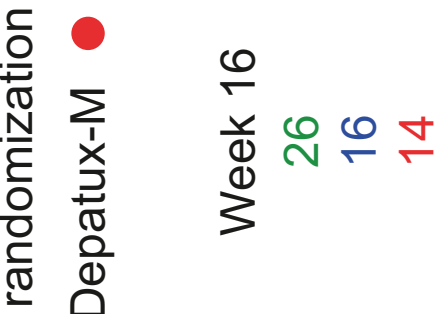

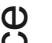

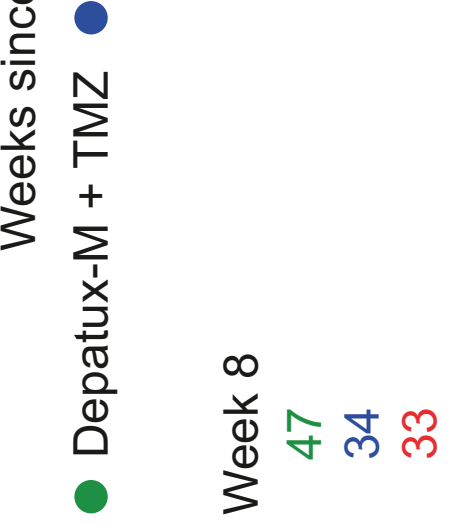


Click here to acces\$/dog/nload;Figure;ABB [2276] Figure 2.eps \pm

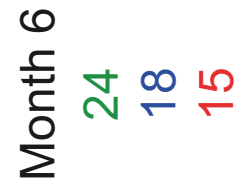

$-\stackrel{+}{ }$

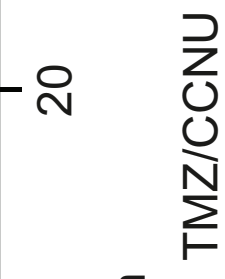

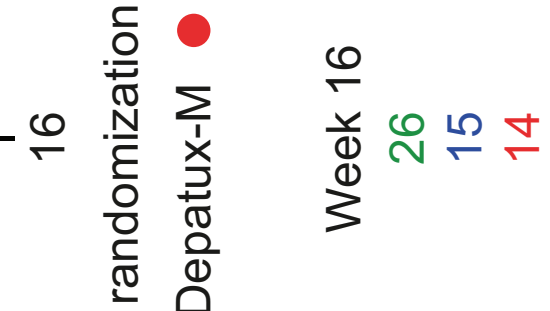

$-\infty$

¿

$\sim$

$\leftarrow$

高



$\stackrel{N}{\Sigma}$

d

$\sum_{x}^{+}$

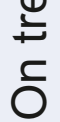
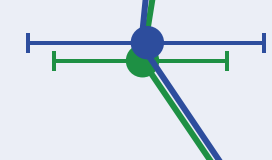

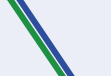

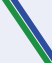

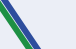

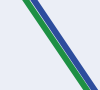

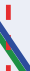

I

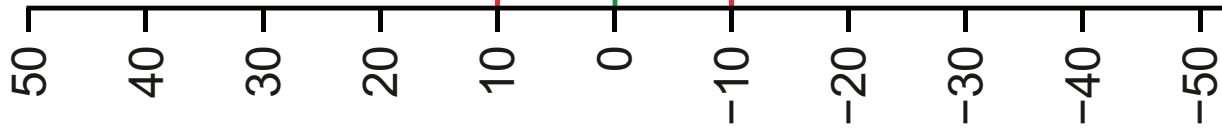

-

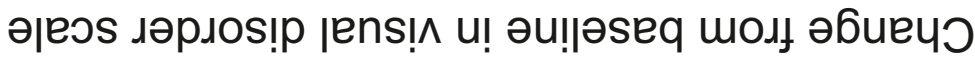

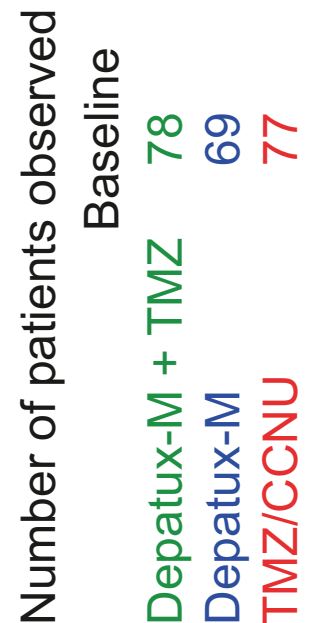




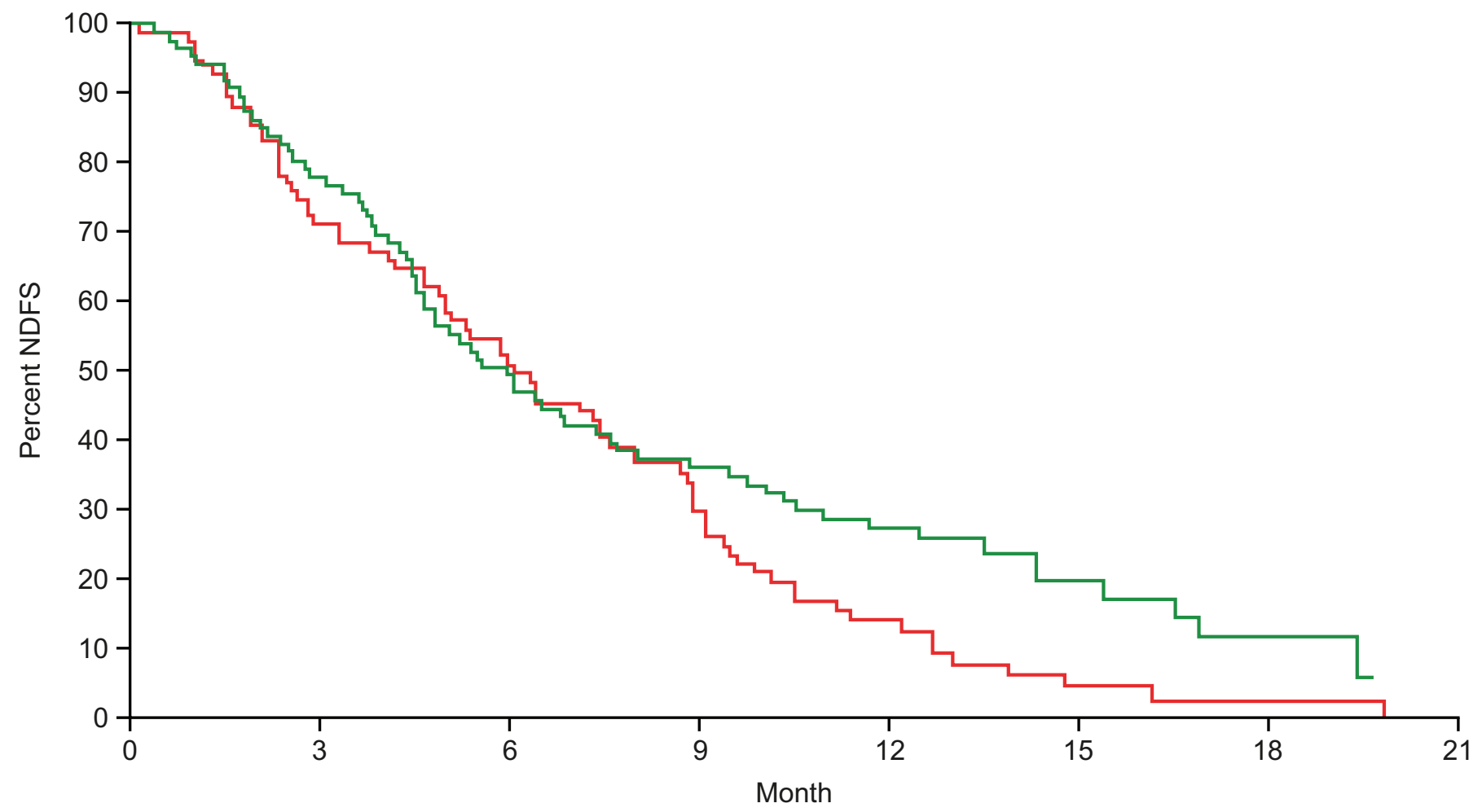

$\frac{\mathrm{O}}{69} \quad \frac{\mathrm{N}}{88}$

Number of patients at risk

65

58
41

39

30
23

23

20
9

20
9
8

2
- Depatux-M + TMZ

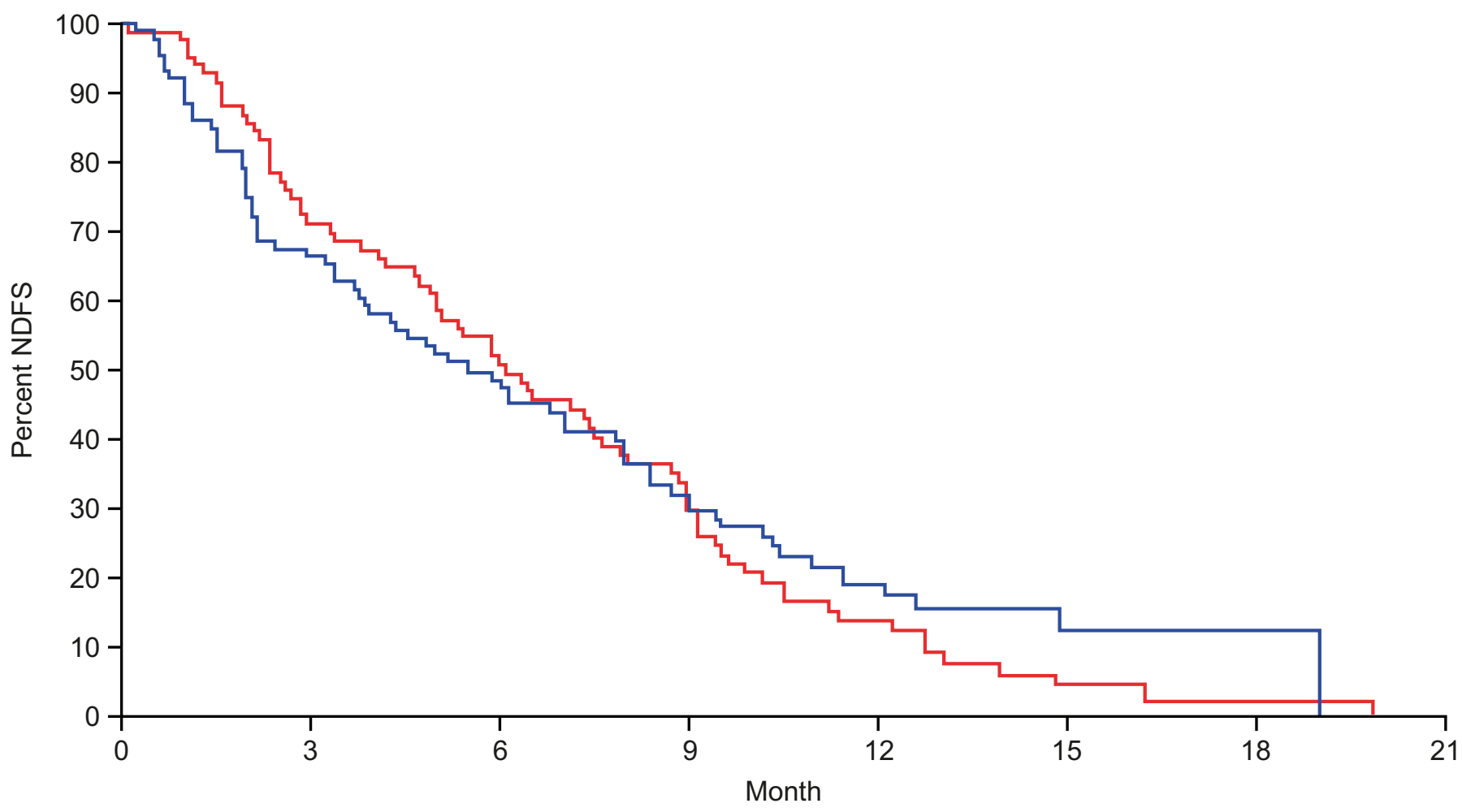

$\frac{\mathrm{O}}{71} \quad \frac{\mathrm{N}}{86}$

$76 \quad 86$
Number of patients at risk

\begin{tabular}{lll}
\hline 57 & 40 & 25
\end{tabular}

39

23

13

9

4

2
- Depatux-M 


\section{Declaration of interests}

The authors declare that they have no known competing financial interests or personal relationships that could have appeared to influence the work reported in this paper.

$\bigotimes$ The authors declare the following financial interests/personal relationships which may be considered as potential competing interests:

Linda Dirven, Sarah Nuyens, Maarten Spruyt, Thierry Gorlia, Corneel Coens, and Jaap C. Reijneveld have nothing to disclose. Paul M. J. Clement received study budget funds from AstraZeneca; was an advisory board member for AbbVie, AstraZeneca, BMS, Daiichi-Sankyo, Leo Pharma, Merck Serono, MSD, and Vifor Pharma. Marica Eoli received consulting fees from AbbVie. Juan M. Sepulveda-Sanchez reports personal fees and non-financial support from AbbVie; a grant from Pfizer as principal investigator; personal fees and non-financial support from Celgene; non-financial support from Ipsen; and personal fees from Astellas. Annemiek M. E. Walenkamp received research grants from IPSEN and Novartis; was an advisory board member for IPSEN, Karyopharm, Novartis, and Polyphor; and received study budget funds from AbbVie, BMS, Genzyme, Karyopharm Therapeutics, and Roche. Jean Sebastien Frenel has received consulting fees from AstraZeneca, BIOCAD, Lilly, Novartis, Pfizer, and Roche. Enrico Franceschi was an advisory board member for Celgene and Karyopharm. Michael Weller has received research grants from AbbVie, Adastra, Merck, Sharp \& Dohme (MSD), Merck (EMD), and Novocure; and honoraria for lectures or advisory board participation or consulting from AbbVie, Basilea, Bristol Myers Squibb (BMS), Celgene, Medac, Merck, Sharp \& Dohme (MSD), Merck (EMD), Nerviano Medical Sciences, Novartis, Orbus, Philogen, Roche, and Tocagen. Olivier Chinot reports personal fees and non-financial support from Abbvie, during the conduct of the study; personal fees from immatics, non-financial support from BMS, non-financial support from Servier, grants, personal fees and non-financial support from Roche, outside the submitted work. Filip Y. F. L. De Vos received research grants from Novartis. Nicholas Whenham has received consulting fees from Bayer and Janssen. Paul Sanghera was an advisory board member for AbbVie and Roche. Jim Looman, Madan G. Kundu, and Jan Peter de Geus are AbbVie employees and may own stock. Vassilis Golfinopoulos received research funding from AbbVie during the conduct of the study. Martin J. van den Bent received consulting fees from AbbVie, Agios, Bayer, Boston Pharmaceuticals, Carthera, Genenta, Karyopharm, and Nerviano. 
Click here to access/download Supplementary Text or Table (online publication only) DV\# 58635_QoL paper EORTC 1410 sup draft FINAL_7Dec2020.docx 


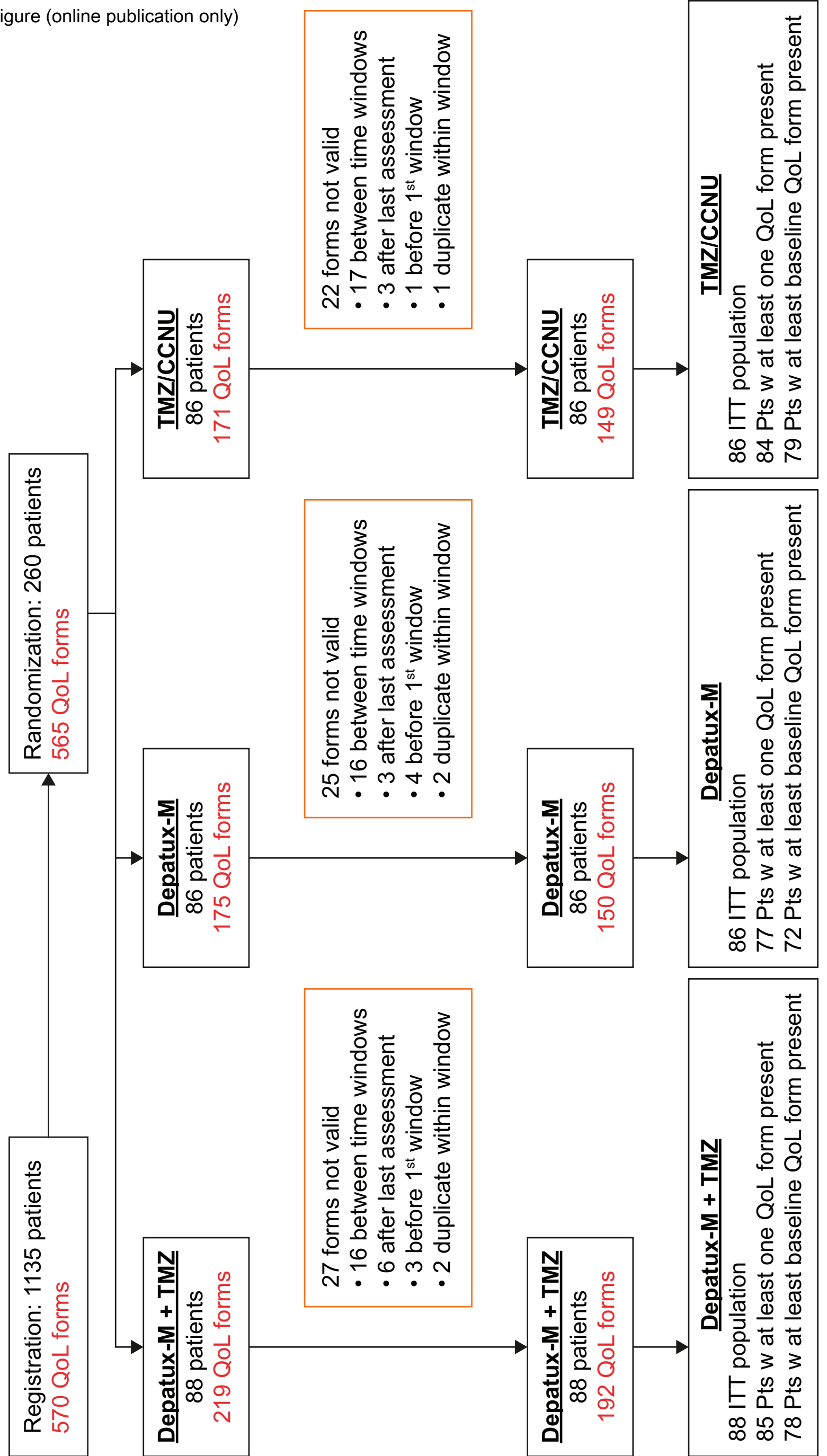




\section{Author contributions}

Study concepts: MvdB

Study design: JL, JPG, CO, JCR MvdB

Data acquisition: PC, ME, JMS, AW, EF, FdV, NW, PS, JCR, MvdB

Quality control of data and algorithms: JL, JPG, CO

Data analysis and interpretation: PC, LD, JL, CO, MvdB,

Statistical analysis: $\mathrm{CO}$

Manuscript preparation: PC, JL, CO, MvdB

Manuscript editing: PC, LD, FdV, JL, CO, MvdB

Manuscript review: All authors 